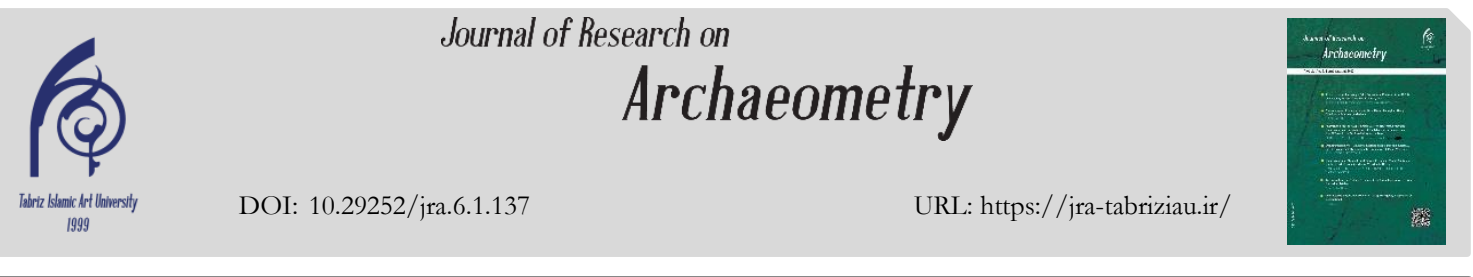

Original Paper

\title{
The Archaeobotanical Studies of Tepe Taleb Khan, Sistan, Southeast of Iran (2500-2300 BCE)
}

\author{
HosseinAli Kavosh ${ }^{1}$, Zohreh Shirazi ${ }^{2 *}$, Reza Naseri ${ }^{3}$ \\ ${ }^{1}$ Assistant professor, Department of Archaeology, University of Zabol, Zabol, IRAN \\ ${ }^{2}$ Archaeobotanist, Archaeobotanical Laboratory, World Heritage Site of Shahr-i Sokhta and Regional \\ Museum of Southeastern Iran, Zahedan, IRAN \\ ${ }^{3}$ Assistant professor, Department of Archaeology, University of Zabol, Zabol, IRAN
}

\author{
Received: 27/01/2020
}

Accepted: $18 / 06 / 2020$

\begin{abstract}
In the third millennium B.C., the inhabitable zones in the southern part of Sistan Plain were confined to the deltaic lands around the Rud-i Biyaban River. One of the main climatological characteristics of that time was the abundance of water resources in the Hilmand basin. The formation and dynamism of human settlements in this region have always been related to the water fluctuations of the Hilmand River, so that a shift in the water courses has always led to changes in human agglomerations. The main purposes of this research are first of all, to find out more about the vegetation around Tepe Taleb Khan and second, to provide more information on the use of these vegetal resources by the local inhabitants in that era. Two phases of archaeobotanical analysis are included in this research: namely field operation (sampling and extracting techniques of plant remains), and laboratory studies on the data coming from the sixth season of archaeological excavations at Tepe Taleb Khan. These studies have been done on the plant remains obtained from 25 samples related to various archaeological contexts such as soil deposit, ashy layer, burnt soil, fireplaces and their contents, plaster and soil deposit, msoil and debris deposit, soil and ash deposit, mudbrick debris and floor (dated back to the third millennium BCE/2500-2300 BCE). By flotation of 316 liter of sediments, collected from these contexts, approximately $1900 \mathrm{~mL}$ plant remains including seeds, rachis segments, fruits and charcoals were extracted. The carpological studies on 2045 seeds, rachis segments and fruits, led to the identification of various vegetal groups with different relative frequencies in the archaeological contexts including cultivated plants (such as cereals, oil seeds, fruits, cucurbits, cultivated pulses) and non-cultivated plants (like wild fruits, wild pulses, wild grasses and wild plants). The results indicated the presence of different crops such as emmer wheat (Triticum dicoccum), free threshing wheat (T. durum/aestivum), bread wheat ( $T$. aestivum), club wheat (T. compactum), spelt (T. spelt), free threshing barley (Hordeum vulgare var.nudum), lentil (Lens culinaris), vetches (Vicia), vetchlings (Lathyrus), pea (Pisum sativum), flax (Linum usitatissimum), grape (Vitis vinifera) and cucurbits (cucurbitaceae), testifying a subsistence economy based on agriculture. At the same time, anthracological studies done on 948 charcoal fragments led to the identification of diffrent trees and shrubs like goosefoots (Chenopodiaceae), tamaris (Tamarix sp.), palm (Phoenix dactylifera) and poplar (Populus sp.). According to the previous archaeobotanical evidence at Shahr-i Sokhta, these taxa are present in the anthracological spectra of the Bronze Age vegetation of the southern Sistan Plain. Based on the archaeobotanical data, Tepe Taleb Khan inhabitants used goosefoots and tamaris wood to meet their fuel needs due to the soft texture and rapid flammability of these species. Nowadays, due to the unfavorable
\end{abstract}

*Corresponding author: zohrehshirazi2003@yahoo.com

Copyright (C) 2020, the Authors / This open-access article is published under the terms of the Creative Commons Attribution-NonCommercial 4.0 International License which permits Share (copy and redistribute the material in any medium or format) and Adapt (remix, transform, and build upon the material) under the AttributionNonCommercial .terms 
environmental conditions of Sistan, tamaris and goosefoots (as xeric and halophytic plants) are the dominant species in the region. The continued presence of these plants from the third millennium B.C., up to now indicates more or less the durability of ecological conditions in the region. The poorness of current vegetation in Sistan has undoubtedly been influenced by environmental and human factors over the time.

Keywords: Archaeology, Archaeobotany, Bronze Age, Sistan plain, Tepe Taleb Khan 


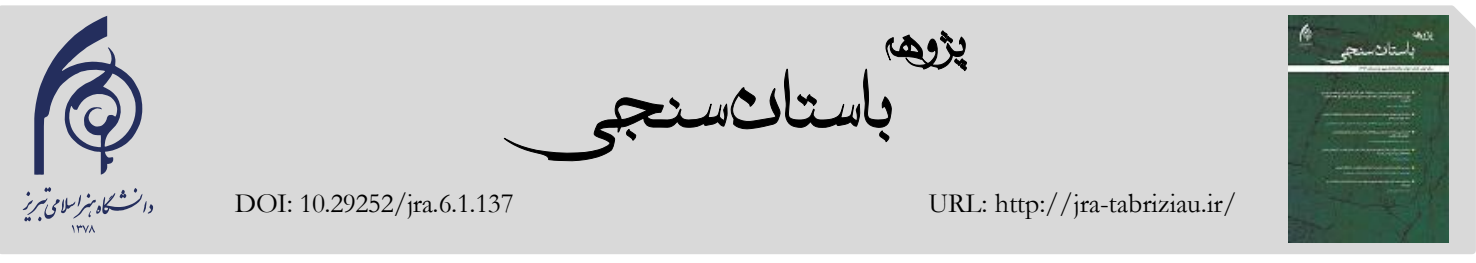

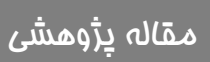

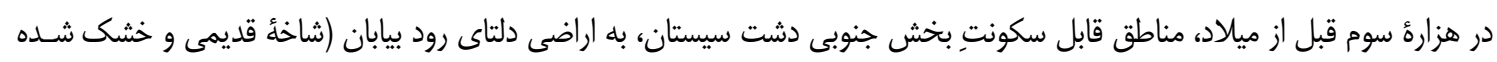

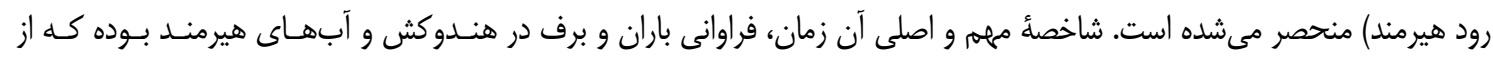

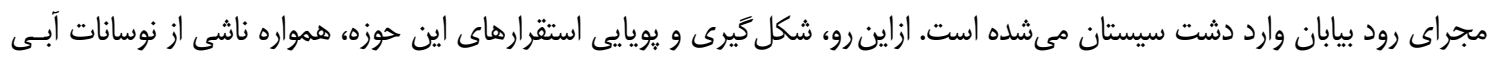

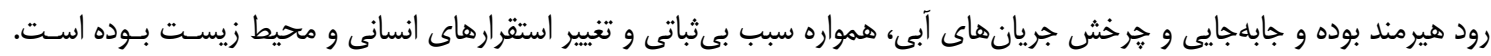

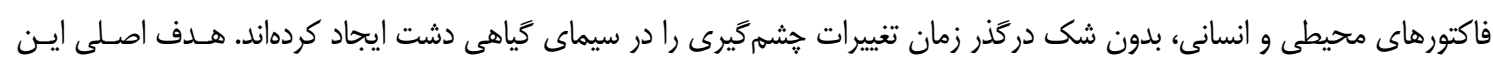

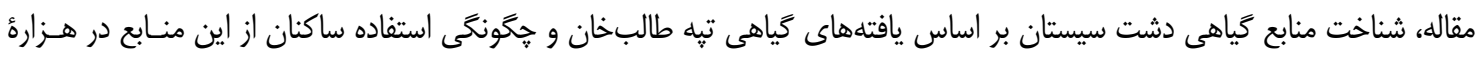

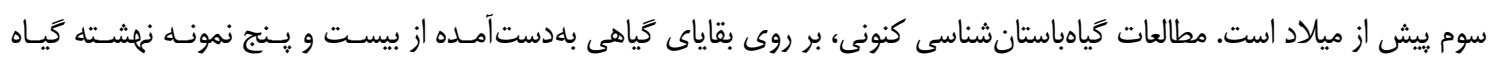

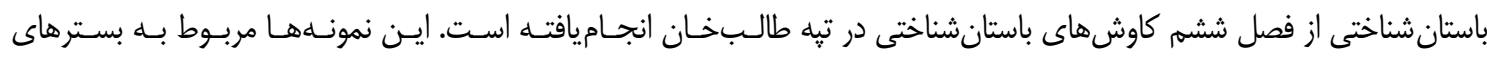

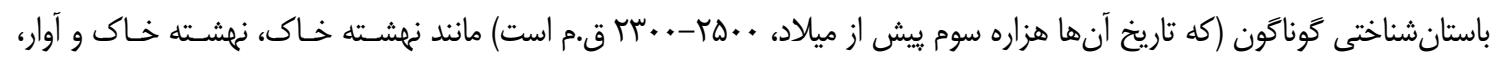

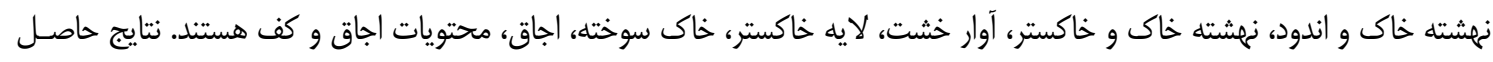

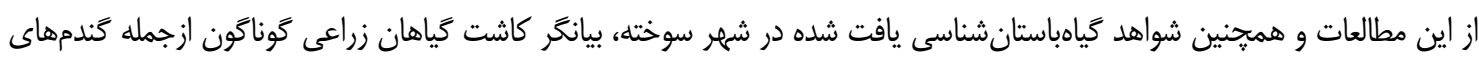

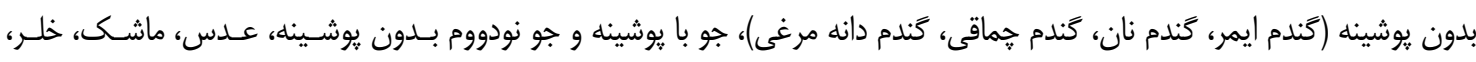

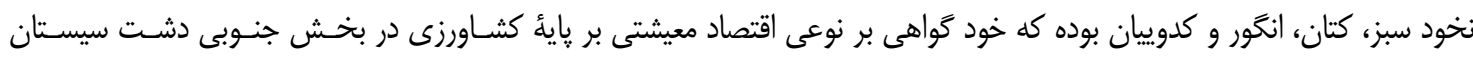

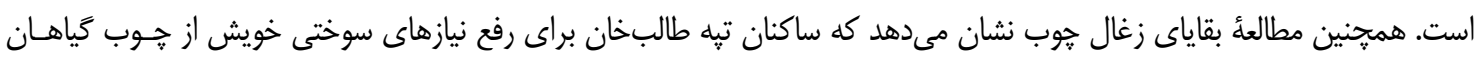

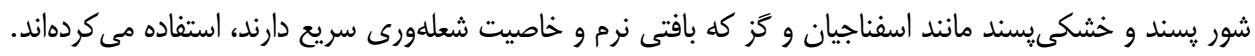

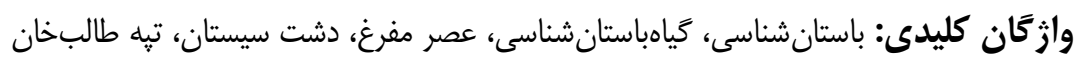

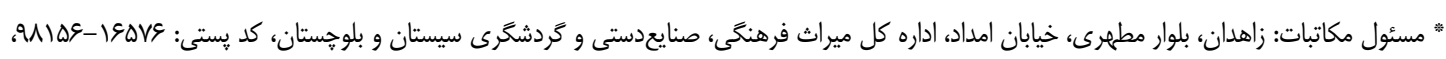

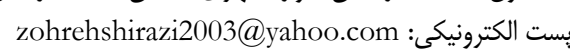
(C) حق نشر متعلق به نويسنده(كان) است و نويسنده تحت مجوز Creative Commons Attribution License به مجله اجازه مى دهد مقاله خاب شده را با ديخران به اشتراك بخذارد منوط بر اينكه حقوق مؤلف اثر حفظ و به به انتشار اوليه مقاله در اين مجله اشاره شود. 
آبنوس (Dalbergia sisso)، صـندل قرمـز ( Adenanthera) و آدينـا كورديفوليـا (cf. pavonina

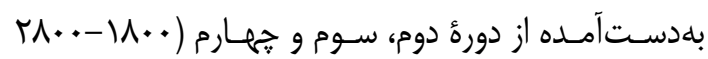
ق.م) در شهر سوخته، بيـانگًر روابـط تجـارى و فرهنخَى

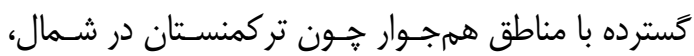

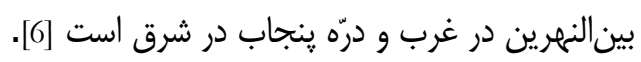
در اين مقاله، بلمنظظور دستيابى بــه اطلاعـات بيشـتر

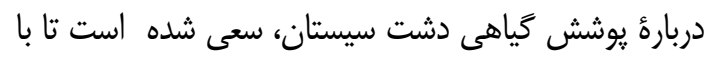

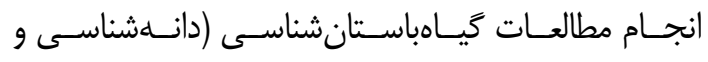
زغالشناسى) بر بقاياى كَاهى (دانه، ميوه، اجزاى سـاقه و

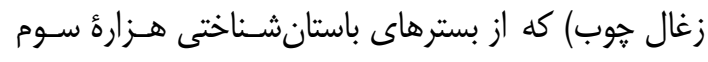

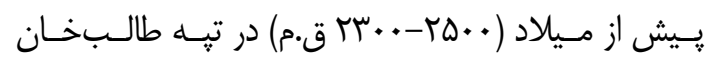

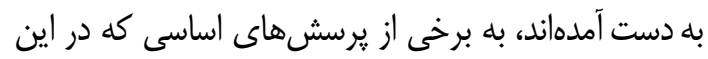

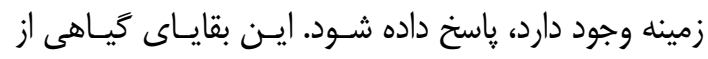

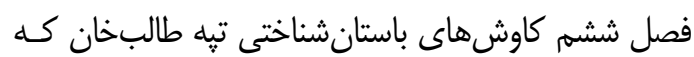

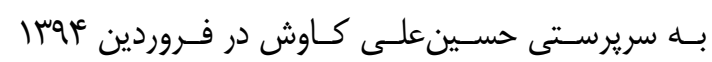

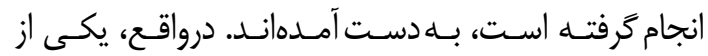

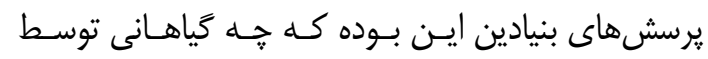

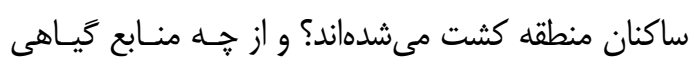
براى تأمين نيازهاى سوختى استفاده مىشده است؟ منى

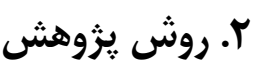

مطالعات كياهباسـتانش شناسـى انجــام گرفتـهـ در قالـب ايـن يزوهش، شـامل دو بخـش عمليـات ميـدانى و مطالعـات

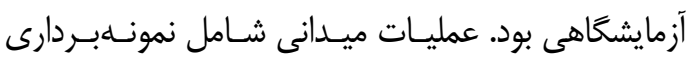
گ ₹ياهباستانشناسى و تكنيك استخراج بقاياى گياهى بـوده و همزمان با كاوش باستانشناسى تئُ طالبخان در سـال

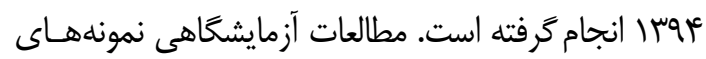

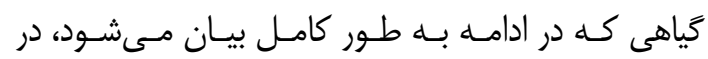

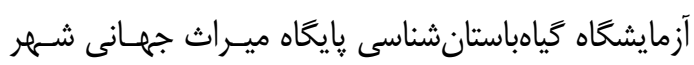
سوخته انجامگرفته است.

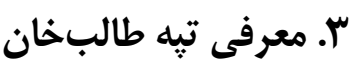

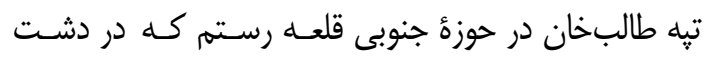

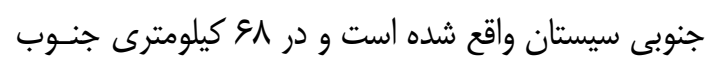
غربى شهرستان زابل در استان سيستان و بلوخستان قـرار

\section{(. مقدمه}

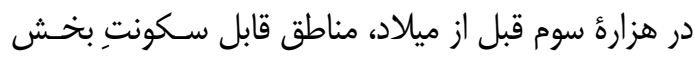
جنوبى دشت سيستان به اراضى دلتاى رود بيابـان (شـاخئ

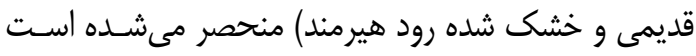

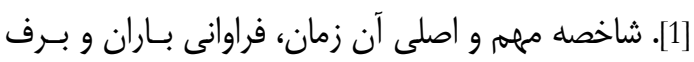

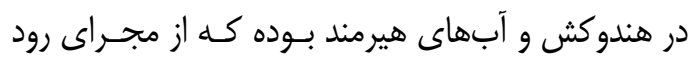

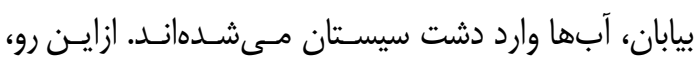
شكل گيرى و يويايى استقرارهاى اين حوزه، همواره ناشسى

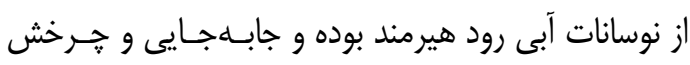

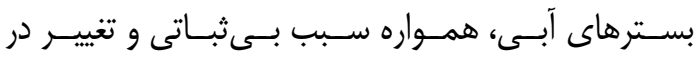

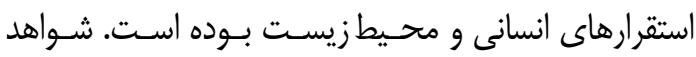

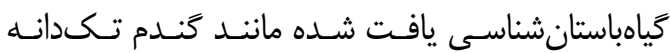
، (Triticum monococcum)

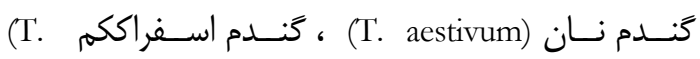

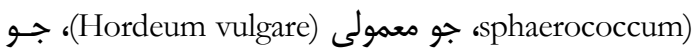
دو رديفــ) (Hordeum vulgare subsp. distichum) ، جـو (H. شش رديفـه (Hordeum vulgare subsp. hexastichum)،

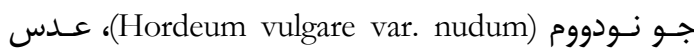

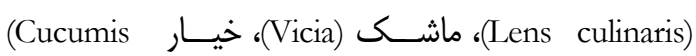

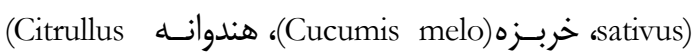

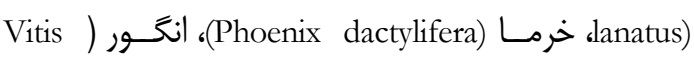
(vinifera سوخته، مركز اصلى تمدن هيرمند، نشان مى دهد كه قبـل

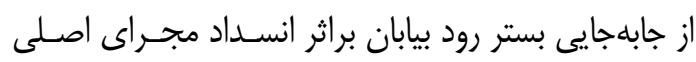
آن، دشت آبرفتى سيستان، جلكَاى حاصلخيز بوده است و

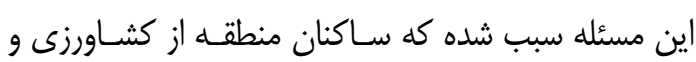

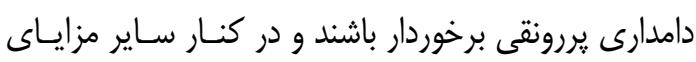

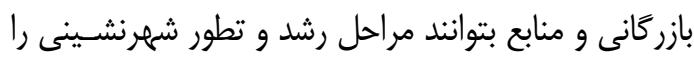

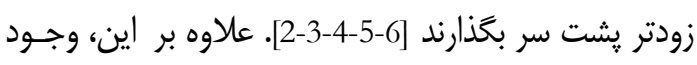

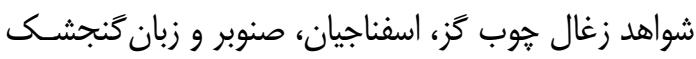
در بسترهاى باستانشناختى هزاره سوم ييش از ميلاد كـهـ به عنوان سوخت، توسط ساكنان منطقه مورداسـتفاده قـرار

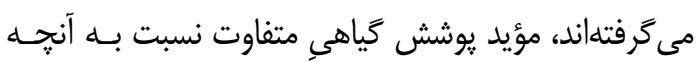

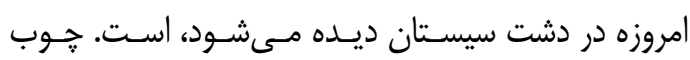

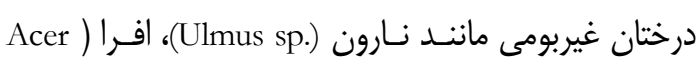

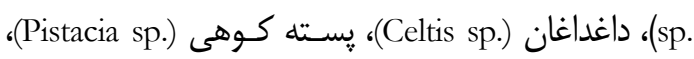

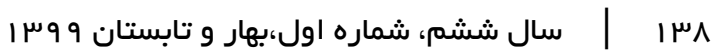


تِّه ماهورها و برجستخى هايى وجود دارند كه جندان مرتفع نيستند و از خاك رسوبى روشن تشكيل شـدهانـد. در حـال

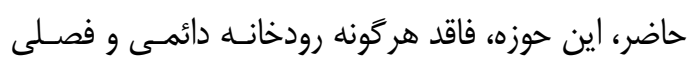

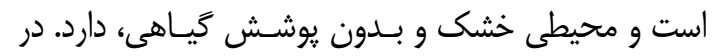

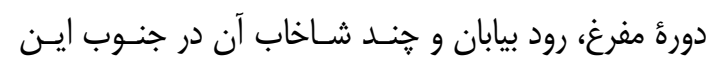

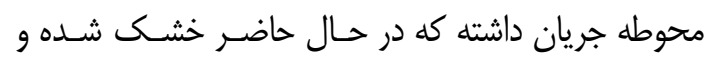

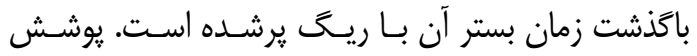

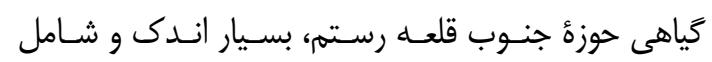

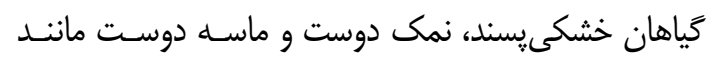
كزها (Tamarix spp.) و اسـناجيان (Chenopodiaceae) از

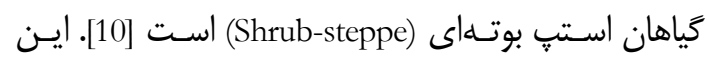

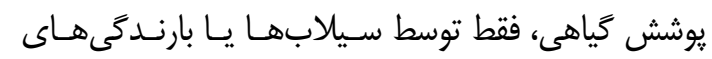
فصلى سيراب مىشود. دشت جنوبى سيستان به دليل عدم

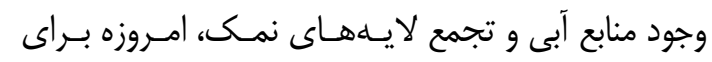
كشاورزى و كشت و زرع مناسب نيست (شكل ()).

\section{ع. مواد و روشها}

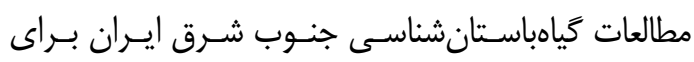

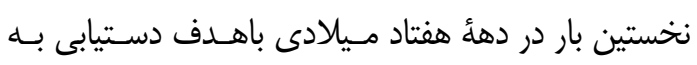

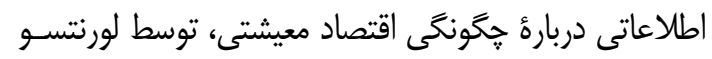

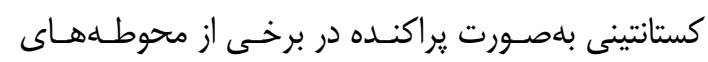
ييش ازتاريخ مانند شهر سوخته [5-4-3-2]، تيه يحيى و كَّز طويله [2-11] انجام كرفت. در سالهاى اخير نيز ماركارتـا

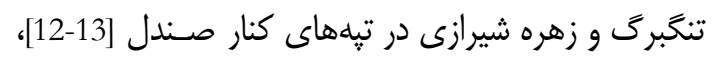
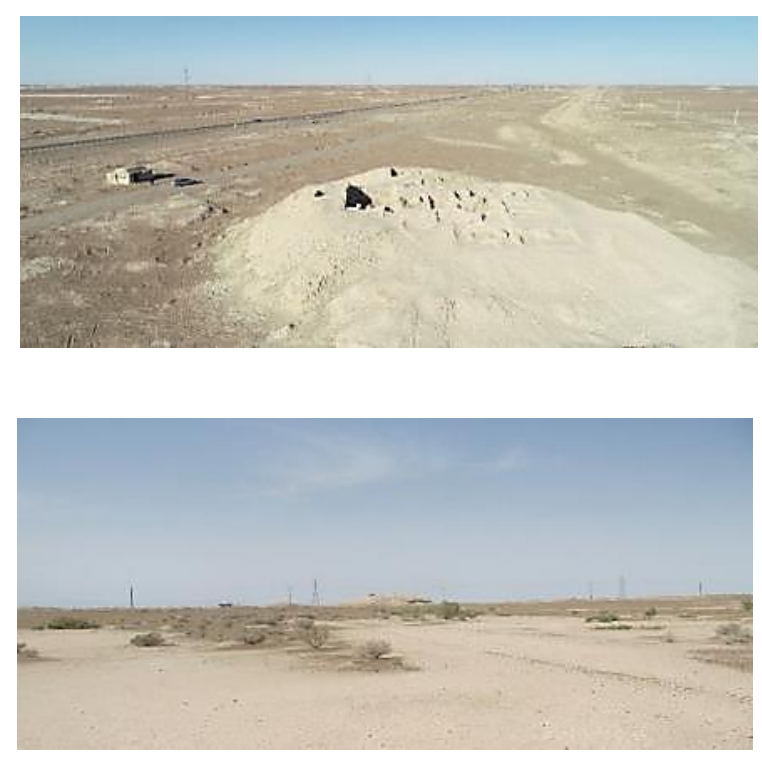

دارد. اين تِه كه مساحت آن حدود نيه هكتار است در كار كيلومترى جنوب محوطة باستانى شهر سوخته قراركرفتهـ

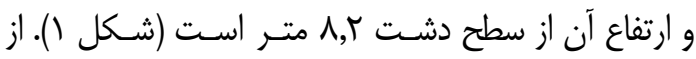

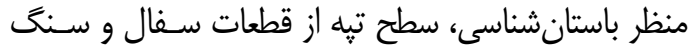
به همراه سرباره فلز و جوش كوره يوشيده شده اسـت. تِّهـ طالبخان در مسير راههاى قديم سيستان به سـرحد قـرار

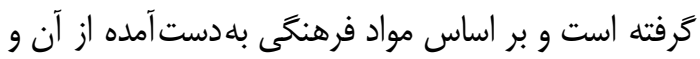

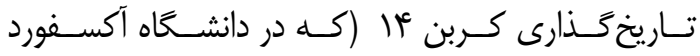

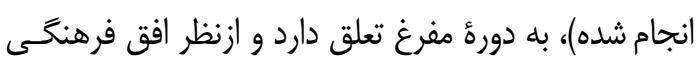

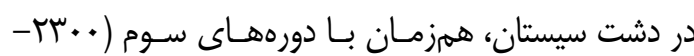

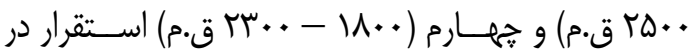

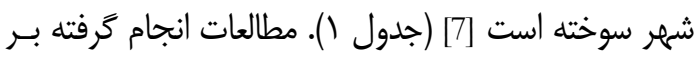
سفالهاى بهدست آمده از فصل ششم كاوش اين محوطه، در مجموع، شِش فرم كلى ظروف سفالى از قبيل كاسهها،

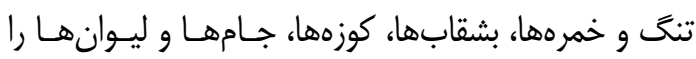
شامل مىشود. اغلب فرمهاى ظـروف سـالى در دورة

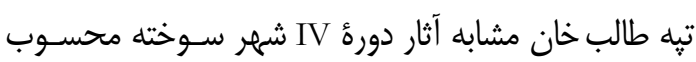

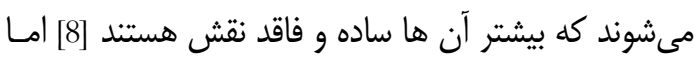

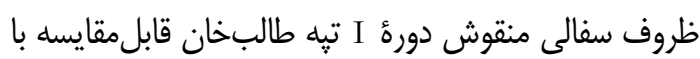

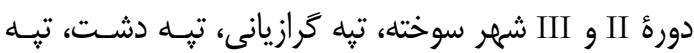

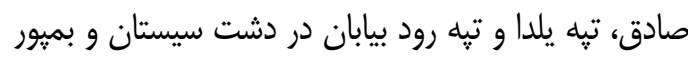

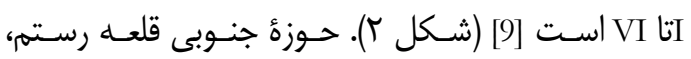
دشتى هموار است كه ارتفاع ميانكين آن از سطح دريا بــهـ

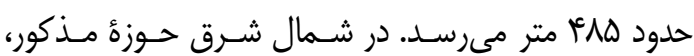

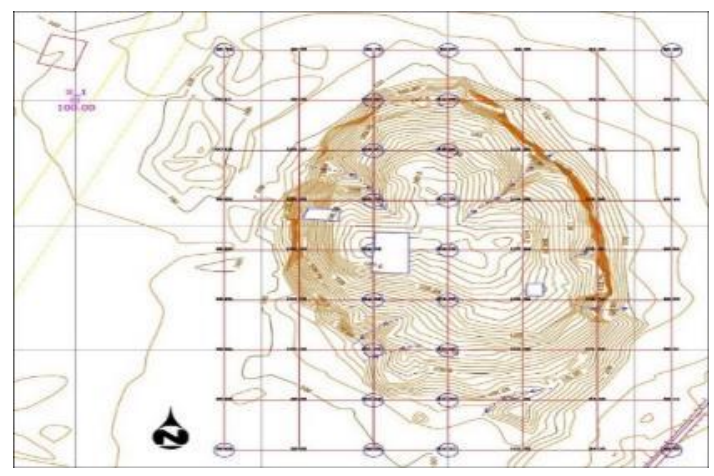

شكل (: نقشه تويوگًر افى محوطه (راست) و نماى كلى تبه طالبخان

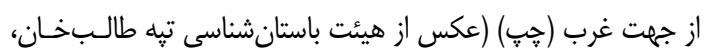

(I)M-1raq

Fig. 1: General view of Tepe Taleb khan from the west (left) and topographic plan of the Site (right) (Photo: Archaeological Mission 


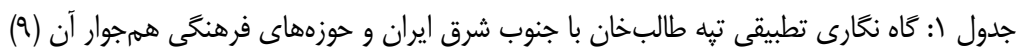

Table 1: Comparative chronology of Tepe Taleb Khan with south east of Iran and its adjacent cultural regions, (9)

\begin{tabular}{|c|c|c|c|c|c|c|c|c|}
\hline \multirow{8}{*}{ 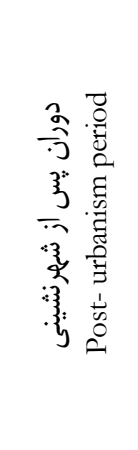 } & \multirow[b]{2}{*}{ B.C } & $\begin{array}{c}\text { افغانستان } \\
\text { Afghanistan } \\
\end{array}$ & \multirow{2}{*}{ Makoran } & \multicolumn{5}{|c|}{$\begin{array}{c}\text { محوطههاى جنوب شرق ايران } \\
\text { Archaeological sites of South East Iran }\end{array}$} \\
\hline & & $\begin{array}{l}\text { مونديگك } \\
\text { Mundigak }\end{array}$ & & $\begin{array}{c}\text { شهداد } \\
\text { Shahdad }\end{array}$ & $\begin{array}{c}\text { تبه يحيى } \\
\text { Tepe } \\
\text { yahya }\end{array}$ & $\begin{array}{c}\text { بميور } \\
\text { Bampour }\end{array}$ & $\begin{array}{c}\text { شهر سوخته } \\
\text { Shahr - i } \\
\text { Sokhta }\end{array}$ & $\begin{array}{c}\text { تيه طالبخان } \\
\text { Tepe Taleb } \\
\text { Khan }\end{array}$ \\
\hline & 1500 & & & \multirow{4}{*}{$\mathrm{II}_{1}$} & \multirow{6}{*}{ IVA } & \multirow{6}{*}{ VI } & \multirow{6}{*}{ IV } & \multirow{8}{*}{ II } \\
\hline & 1600 & & & & & & & \\
\hline & 1700 & & & & & & & \\
\hline & 1800 & & & & & & & \\
\hline & 1900 & \multirow{8}{*}{$\begin{array}{l}I V_{1} \\
I V_{2} \\
I V_{3}\end{array}$} & & $\mathrm{II}_{2}$ & & & & \\
\hline & 2000 & & \multirow{4}{*}{$\mathrm{III}_{\mathrm{C}}$} & \multirow{3}{*}{$\mathrm{III}_{1}$} & & & & \\
\hline & 2100 & & & & \multirow{3}{*}{ IVB } & \multirow{3}{*}{$\mathrm{V}$} & \multirow{3}{*}{ III } & \\
\hline$\cdot \overrightarrow{0}$ & 2200 & & & & & & & \\
\hline 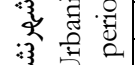 & 2300 & & & \multirow{2}{*}{$\mathrm{III}_{2}$} & & & & \multirow{2}{*}{ I } \\
\hline 然苛 & $\frac{2400}{2500}$ & & \multirow{3}{*}{$\mathrm{III}_{\mathrm{B}}$} & & \multirow{3}{*}{ IVC } & IV & \multirow{4}{*}{ II } & \\
\hline $\overrightarrow{0}$ & 2600 & & & & & III & & \\
\hline$\frac{2}{.5}$ & 2700 & & & $\mathrm{IV}_{1}$ & & & & \\
\hline : & $\begin{array}{l}2800 \\
2900\end{array}$ & \multirow{4}{*}{ III } & \multirow{4}{*}{$\mathrm{III}_{\mathrm{A}}$} & \multirow{3}{*}{$\mathrm{IV}_{2}$} & & \multirow[t]{4}{*}{ I-II } & & \\
\hline 芳 & 3000 & & & & \multirow{3}{*}{ VA } & & \multirow{3}{*}{ I } & \\
\hline 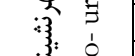 & 3100 & & & & & & & \\
\hline . $\begin{array}{r}0 \\
0 \\
0\end{array}$ & 3200 & & & & & & & \\
\hline
\end{tabular}

ديرينزيستمحيطى اشاره كرد كه در حوزه جنـوب شـرق

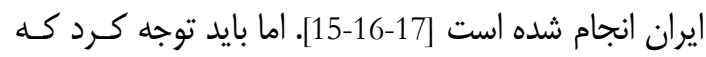
فقط يكى از اين مطالعات، داراى جدول زمانى مبتــى بـــر

تاريخيابى مطلق است [15].
تيه كَاو كشى (منتشرنشــده)، تـل آتشـى در دارسـتان بـمم

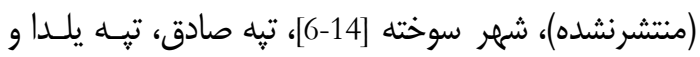

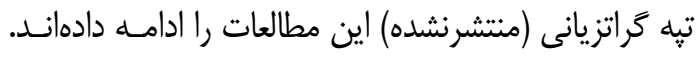

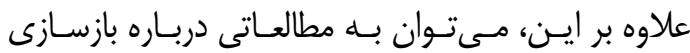

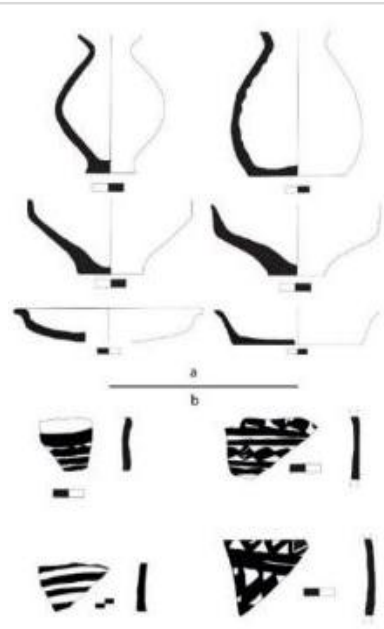

ه Relative frequency / فراوانى نسبى
فراوانى نسبى فرمهاى ظروف سفالى

Relative frequency of pottery vessel forms

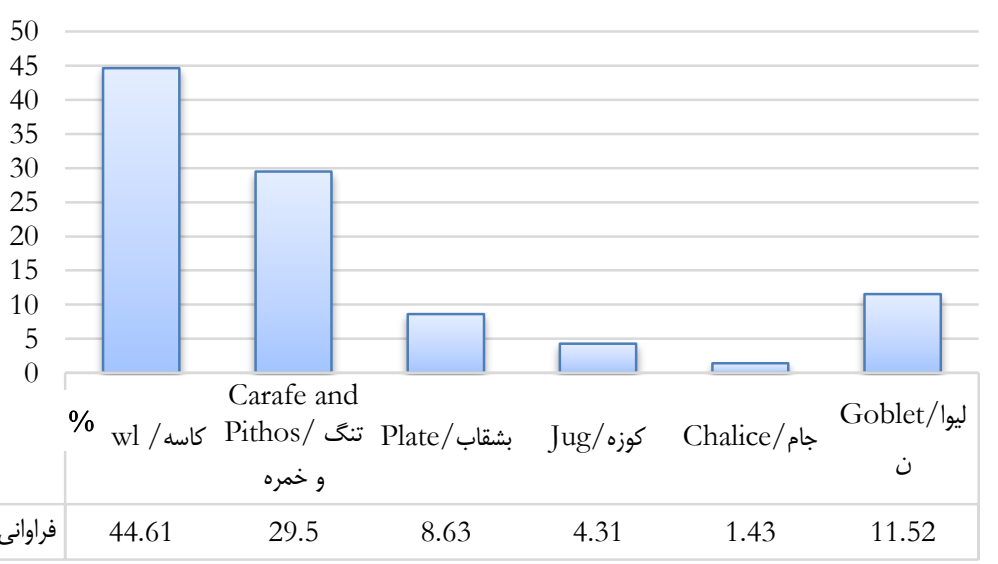

شكل r: سفال هاى تبه طالبخان، دوره II و II (a) و فراوانى نسبى فرمهاى ظروف سفالى بلدست آمده از ششمين فصل كاوش طالبخان Fig. 2: Tepe Taleb Khan potteries, period II (a) and I (b) and relative frequency of pottery vessel forms from sixth season of excavation in Tepe Taleb Khan 
بسيار كم بود و از شناورسازى اين نوع نهشتهها در برخى

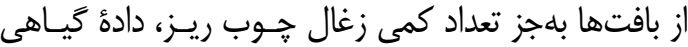

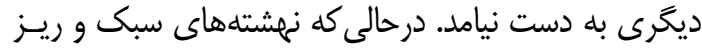

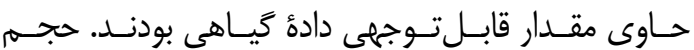

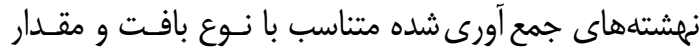

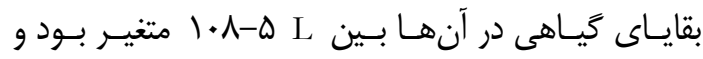
درمجموع حدود L عاس نهشتهٔ حاوى بقاياى كَياهى جهت

$$
\text { شناورسازى برداشت شد (جدول r). }
$$

ع-1. نمونهبردارى كَياهباستانشناسى

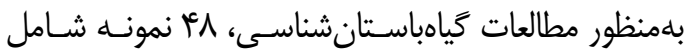

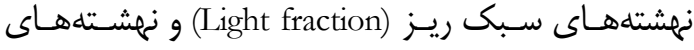

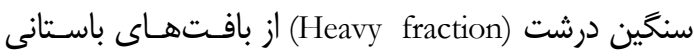

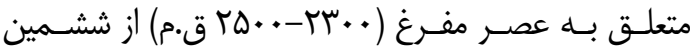

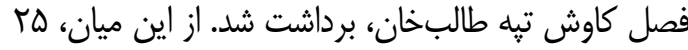

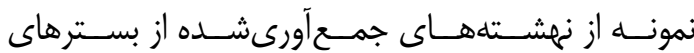
باستانشناختى مانند نهشته خـاك، لايـه خاكسـتر، خـاك

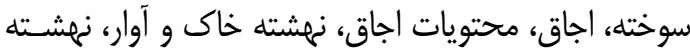

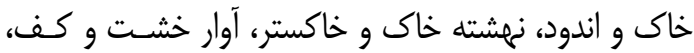

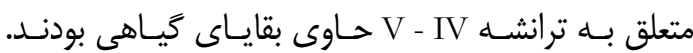
بيشترين فراوانى نسبى نهشتههاى حاوى بقايـاى خيـاهى،

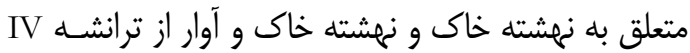
بودند و ساير بافتهــا، فراوانى نسـبى كمتـرى داشـتند

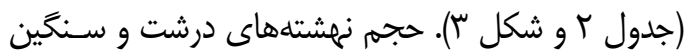

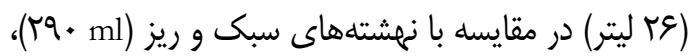

جدول זَ: يراكندگى نهشتههاى داراى بقاياى گياهى در بافتار باستانى تبه طالبخان

Table 2: Distribution of sediments containing plant remains in archaeological contexts at Tepe Taleb Khan

\begin{tabular}{|c|c|c|c|c|c|c|}
\hline \multicolumn{2}{|c|}{$\begin{array}{c}\text { نوع بقاياى گياهى } \\
\text { Type of remains plant }\end{array}$} & \multicolumn{2}{|c|}{$\begin{array}{l}\text { نهشتهاى داراى بقاياى كياهى } \\
\text { Deposits with remains plant }\end{array}$} & \multicolumn{2}{|c|}{$\begin{array}{c}\text { نهشتهاى جمع آورىشده } \\
\text { Collected deposits }\end{array}$} & \multirow{2}{*}{$\begin{array}{c}\text { بافت باستانى } \\
\text { Archaeological context }\end{array}$} \\
\hline زغال جوب & $\begin{array}{c}\text { دانه، ميوه و اجزاى ساقه } \\
\text { Seed, fruitr, rachis segment }\end{array}$ & $\begin{array}{l}\text { درصد } \\
\%\end{array}$ & $\begin{array}{l}\text { تعداد } \\
\text { N }\end{array}$ & $\begin{array}{l}\text { مرصد } \\
\%\end{array}$ & $\begin{array}{l}\text { تعداد } \\
\text { N }\end{array}$ & \\
\hline$*$ & & $\% 4$ & 1 & $\% 4$ & 2 & كurface soil layer \\
\hline$*$ & $*$ & $\% 8$ & 2 & $\% 8$ & 4 & $\begin{array}{l}\text { Ashy layer } \\
\text { خاكستر } \\
\end{array}$ \\
\hline$*$ & $*$ & $\% 4$ & 1 & $\% 4$ & 2 & 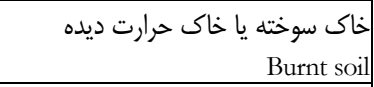 \\
\hline$*$ & $*$ & $\% 4$ & 1 & $\% 4$ & 2 & $\begin{array}{r}\text { (جاق } \\
\text { Fireplace } \\
\end{array}$ \\
\hline$*$ & & $\% 8$ & 2 & $\% 8$ & 4 & $\begin{array}{l}\text { محتويات درون اجاق } \\
\text { Fireplace contents }\end{array}$ \\
\hline$*$ & $*$ & $\% 20$ & 5 & $\% 21$ & 10 & $\begin{array}{r}\text { Sشil deposit } \\
\text { Soil }\end{array}$ \\
\hline$*$ & $*$ & $\% 24$ & 6 & $\% 23$ & 11 & $\begin{array}{r}\text { Pزشته خاكى و آوار، نهشته خاك و اندود } \\
\text { Plaster and soil deposit, Soil and } \\
\text { debris deposit }\end{array}$ \\
\hline$*$ & $*$ & $\% 4$ & 1 & $\% 4$ & 2 & \begin{tabular}{|c|} 
Soil and ash deposit \\
خهشته و خاكستر
\end{tabular} \\
\hline$*$ & $*$ & $\% 8$ & 2 & $\% 8$ & 4 & $\begin{array}{r}\text { آوار خشت } \\
\text { Mudbrick debris } \\
\end{array}$ \\
\hline$*$ & $*$ & $\% 16$ & 4 & $\% 15$ & 7 & $\begin{array}{r}\text { Sloor } \\
\text { Flor }\end{array}$ \\
\hline & & $\% 100$ & 25 & $\% 100$ & 48 & مجموع \\
\hline
\end{tabular}


جدول "َ. نمونهبردارى كَياهباستانشناسى در تَه طالبخان

Table 3: Archaeobotanical sampling at Tepe Taleb Khan

\begin{tabular}{|c|c|c|c|c|c|c|c|c|c|c|}
\hline تراكم & تعاياى & حاصل از شناورسازى گياهى & حجم نهشته قبل & تاريخ تقريبى & فاز محلى & دوره & عمق & نوع بافت & بافت & ترانشه \\
\hline $\begin{array}{l}\mathrm{N} . \mathrm{R} \\
/ \mathrm{L} \\
* * * *\end{array}$ & $\begin{array}{l}\text { N. R } \\
* * *\end{array}$ & $\begin{array}{l}\text { Vol. of remains } \\
\text { plant after } \\
\text { flotation }(\mathrm{ml} .)^{* *}\end{array}$ & $\begin{array}{l}\text { Vol. of deposits } \\
\text { before flotation } \\
\text { (L) }{ }^{*}\end{array}$ & $\begin{array}{l}\text { Approximate } \\
\text { date }(\mathrm{BC})\end{array}$ & Local phase & Period & $\begin{array}{l}\text { Depth } \\
(\mathrm{cm})\end{array}$ & Archaeological context & $\begin{array}{l}\text { Context } \\
\text { number }\end{array}$ & Trench \\
\hline 0 & 0 & 5 & 16 & $2500-2300$ & $\begin{array}{l}\text { Shahr - i Sokhta } \\
\text { سوخته بهر شII }\end{array}$ & $\begin{array}{c}\text { مفرغ } \\
\text { Bronze }\end{array}$ & 88 & $\begin{array}{l}\text { لايه خاى سطحى } \\
\text { Surface soil layer }\end{array}$ & 4000 & IV \\
\hline $4 / 4$ & 483 & 898 & 108 & $2500-2300$ & $\begin{array}{l}\text { Shahr - i Sokhta } \\
\text { سوخته بشر شII }\end{array}$ & مفرغ & $\begin{array}{c}13,20,22 \\
31,45\end{array}$ & نهشته خاك & $\begin{array}{l}4001 \\
4002 \\
4007 \\
4010 \\
4022\end{array}$ & IV \\
\hline $0 / 4$ & 24 & 27 & 51 & $2500-2300$ & $\begin{array}{l}\text { Shahr - i Sokhta } \\
\text { سوخته س شهر III }\end{array}$ & مفرغ & $88,90,100$ & $\begin{array}{l}\text { نهشتته خاك و آوارSoil } \\
\text { and debris deposit }\end{array}$ & $\begin{array}{l}4013 \\
4016 \\
4040 \\
4041 \\
4053\end{array}$ & IV \\
\hline $2 / 9$ & 38 & 25 & 13 & $2500-2300$ & $\begin{array}{l}\text { Shahr - i Sokhta } \\
\text { III شوخته بهر }\end{array}$ & مفرغ & 31,140 & $\begin{array}{l}\text { لايه خاكستر } \\
\text { Ashy layer }\end{array}$ & $\begin{array}{l}4019 \\
4057\end{array}$ & IV \\
\hline 11 & 619 & 263 & 54 & $2500-2300$ & $\begin{array}{l}\text { Shahr - i Sokhta } \\
\text { سوخته ش شهر III }\end{array}$ & مفرغ & 25 & $\begin{array}{c}\text { كloor } \\
\text { Floor }\end{array}$ & $\begin{array}{l}4021 \\
4024 \\
4031 \\
4032\end{array}$ & IV \\
\hline 2 & 43 & 58 & 21 & $2500-2300$ & $\begin{array}{l}\text { Shahr - i Sokhta } \\
\text { سوخته بهر شII }\end{array}$ & مفرغ & 94,101 & $\begin{array}{c}\text { آوار خشت } \\
\text { Mudbrick debris }\end{array}$ & $\begin{array}{l}4023 \\
4045\end{array}$ & IV \\
\hline 55 & 385 & 140 & 7 & $2500-2300$ & $\begin{array}{l}\text { Shahr - i Sokhta } \\
\text { III شوخته بهر }\end{array}$ & مفرغ & & خاك سوخته & 4025 & IV \\
\hline 19 & 135 & 136 & 7 & $2500-2300$ & $\begin{array}{l}\text { Shahr - i Sokhta } \\
\text { سوخته س شهر III }\end{array}$ & مفرغ & & $\begin{array}{c}\text { اجاق } \\
\text { Fireplace } \\
\end{array}$ & 4026 & IV \\
\hline 38 & 310 & 252 & 8 & $2500-2300$ & $\begin{array}{l}\text { Shahr - i Sokhta } \\
\text { سوخته سهر III }\end{array}$ & $\begin{array}{c}\text { مفرغ } \\
\text { Bronze }\end{array}$ & & $\begin{array}{l}\text { نهشته خاك و خاكستر } \\
\text { Soil and ash deposit }\end{array}$ & 4030 & IV \\
\hline 0 & 0 & 10 & 5 & $2500-2300$ & $\begin{array}{l}\text { Shahr - i Sokhta } \\
\text { III شوخته بهر }\end{array}$ & مفرغ & 125 & $\begin{array}{c}\text { محتويات درون اجاق } \\
\text { Fireplace } \\
\text { contents }\end{array}$ & 4061 & IV \\
\hline $0 / 5$ & 8 & 10 & 15 & $2500-2300$ & $\begin{array}{l}\text { Shahr - i Sokhta } \\
\text { سوخته r شهر III }\end{array}$ & مفرغ & & $\begin{array}{l}\text { Plaster and soil deposit } \\
\text { Pشته خاك و اندود }\end{array}$ & 5010 & $\mathrm{~V}$ \\
\hline 0 & 0 & 76 & 11 & $2500-2300$ & $\begin{array}{l}\text { Shahr - i Sokhta } \\
\text { III شوخته بهر }\end{array}$ & مفرغ & 250 & $\begin{array}{l}\text { محتويات درون اجاق } \\
\text { Fireplace contents }\end{array}$ & 5023 & $\mathrm{~V}$ \\
\hline & 2045 & 1900 & 316 & & & & & & \multicolumn{2}{|c|}{ Tota / مجموع } \\
\hline
\end{tabular}

* Litre; ** Mililitre; *** Number Remains; **** Number Remains /Litre

أزمايشگاهى و ميكروسكويى داشـتند. ايـن مطالعـات كـهـ شامل مراحـل مختلـف آزمايشـكاهى بـود در آزمايشـاهـاه كياهباستانشناسى باييخاه ميراث جهانى شهر سوخته، انجام

$$
\text { شد. اين مراحل، عبارت بودند ازئ }
$$

الف. مرحله جداسازى بقاياى گياهى: بقايـاى گيـاهى

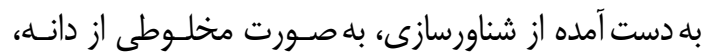

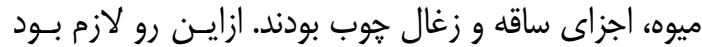

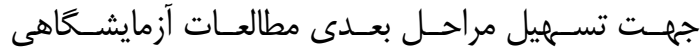
(دانهشناسى و زغالشناسى) اين دادهها از يكديكر تفكيى ماتى
زغال جوب بهدست آمد (جـدول سَ). در برخسى از بافتهــا

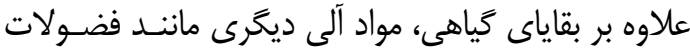

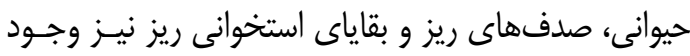

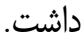

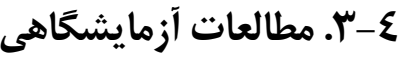

بررسى اولية بقاياى كياهى حاصل از شناورسـازى، نشـان

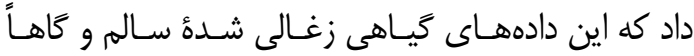

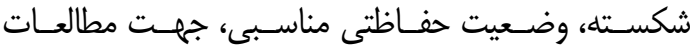

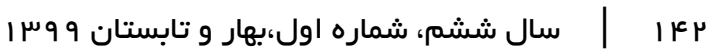


كَياهباستانشناسى پايخاه ميـراث جهـانى شهر سـوخته

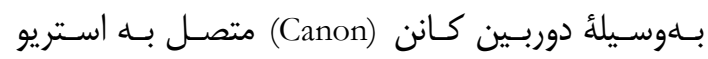

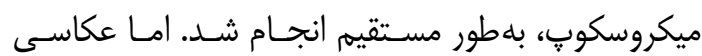

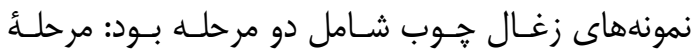

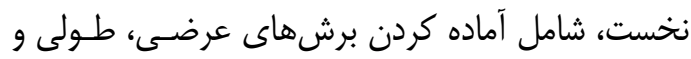

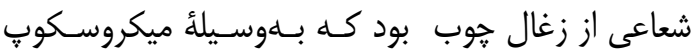

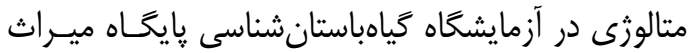

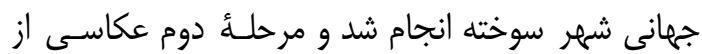

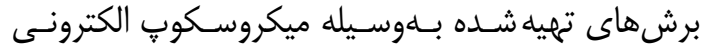
روبشى Scanning Electronic Microscope SEM) بـود كه در آزمايشعاه مركزى دانشعاه سيسـتان و بلوجٍــتان

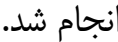

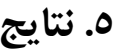

\section{0-1 (. مطالعات دانهشناسى}

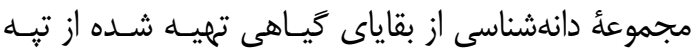
طالبخان، شامل بقاياى دانه، ميـوه و اجـزاى سـاقه بــود.

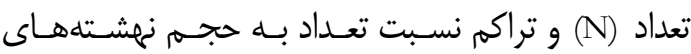
جمع آورى شده قبل از شناورسازى برحسب ليتر (N/L:
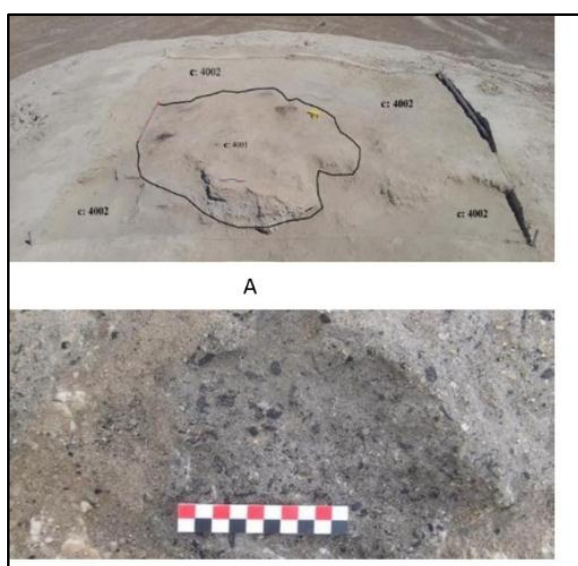

C

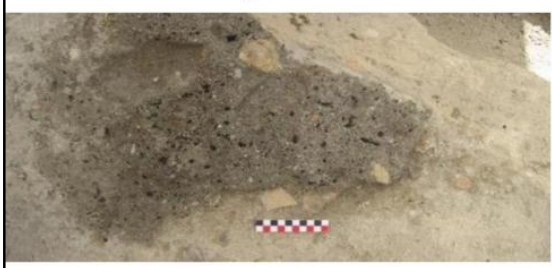

$E$

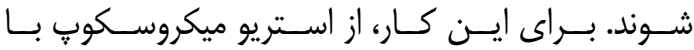
بزركَنمايى x80 مدل NSZ-810 استفاده شد. در پايان اين مرحله كه بسيار دشوار و زمانبر بود، دو نوع بقاياى تياهى

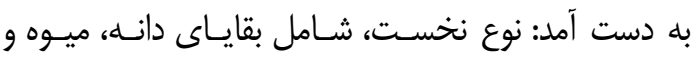
اجزاى ساقه و نوع ديخر شامل بقاياى زغال جوب بود. ب. مرحلهُ مطالعات دانهشناسى: ايـن مرحلـه، شـامل مشاهدة ميكروسكويى بقاياى دانه، ميوه و اجزاى سـاقه و

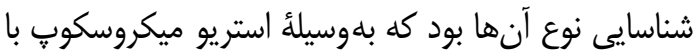

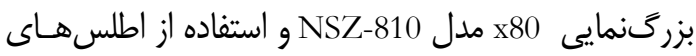
توصيفى دانه و ميوه انجام شد [22-21-21-19-18]. ج. مرحلة مطالعات زغالشناسى: ايـن مرحلـه شـامل

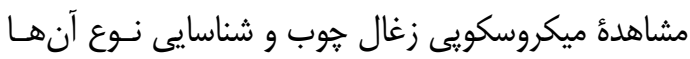

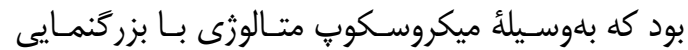

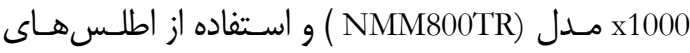
تشريحى جوب [28-27-26-24-23] و كلكسيون مرجـع موجود در آزمايشكاه انجام شد.

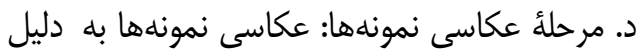

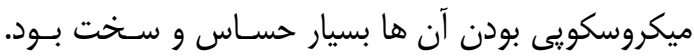

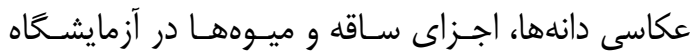

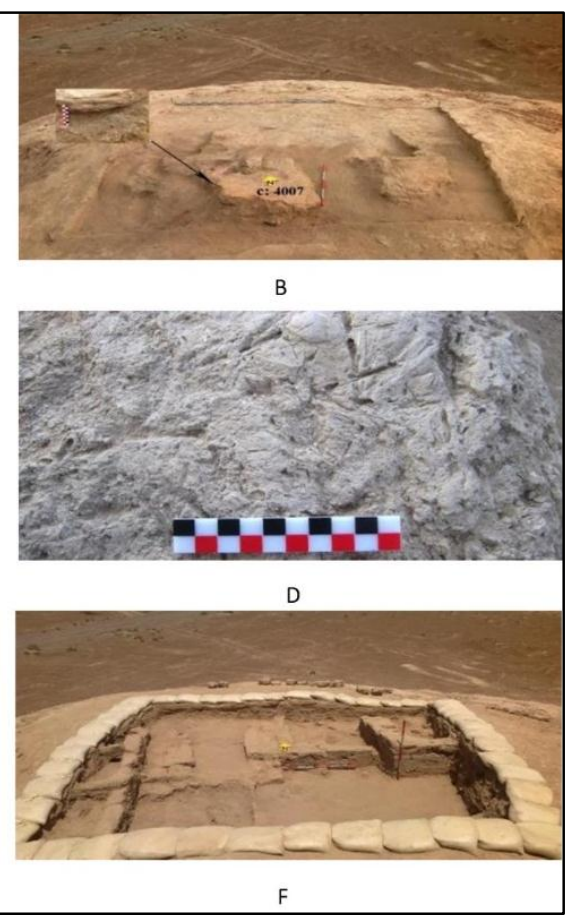

شكل "ّ: بافتار باستانى كه نمونهبردارى كَيامباستانشناسى در آنها انجامَّرفته است: نهشته خاك (D/4031) (A/4001-4002, B/4007, C/4022)،

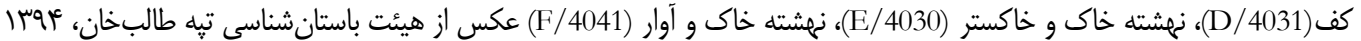
Fig. 3: Archaeological contexts, subjected to archaeobotanical samplings: soil deposit (A/4001-4002, B/4007, C/4022), floor (D/4031), soil and ash deposit (E/4030), soil and debris deposit (F/4041) (Photo: Archaeological Mission of Tepe Taleb Khan, 2016) 
جماقى (T. Compactum)، گَندم دانه مرغى (T. spelta) و

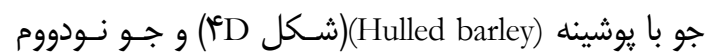

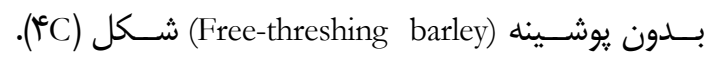
تعدادى از دانهها به دليـل آسـيبديـدگى قابـل شناسـايى

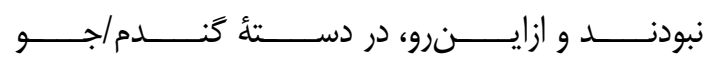
(Triticum sp.) و كندم: (Triticum/Hordeum) يا غـلات ناشـناخته (Indeterminate Cereals) جـاىداده

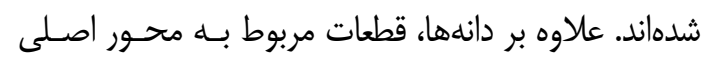
كلآذين (rachis segment) مانند ميان گره (Internode) و سنبلجه (Spikelet forks) متعلق به كَندم ايمر و گَندم نـان

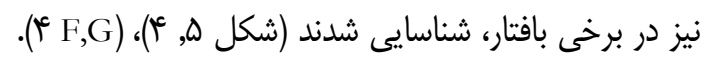

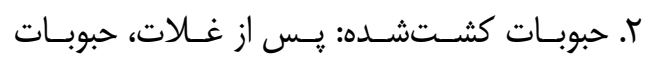

كشت شده، بيشترين تعداد دانههـاى شناسـايى شـده (T)

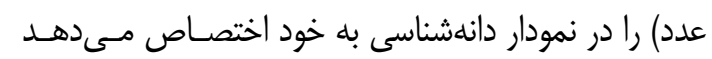

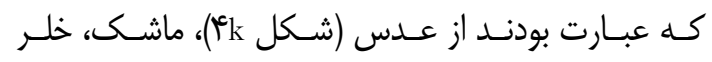
(I) و نخود سبز (Lathyrus sp.)

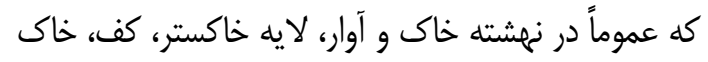
حرارت ديده و اجاق شناسايىشدهاند (شكل ع).

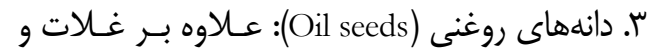
حبوبات كشت شده، جهبارده دانه كتان از خـانواده كتانيـان خو متعلق به كروه دانههاى روغنـى در نهشــانه (Linaceae)

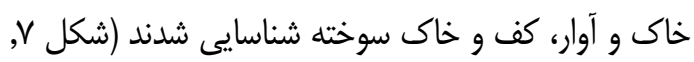

؟ا. ميوهها: دو عدد هسته زغالى شده انغخور از خـانواده

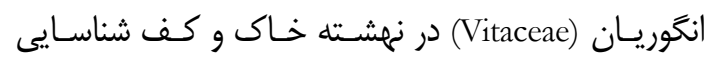

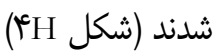

ه. صيفى جات: در نهشتههاى جمع آورى شده از كـف، يك عدد هسته زغالى شده متعلـق بــه خـانواده كـدوييان (Cucurbitaceae)

\section{ب. كَياهان غير كشتشده}

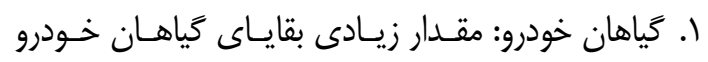

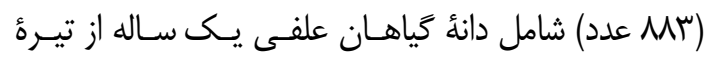

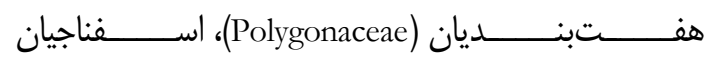

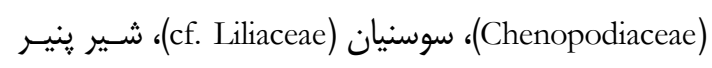

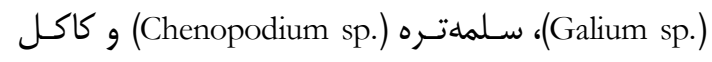

اين بقايا نسبت بله حجــم نهشـتهـــاى جمـع آورىشــــاز

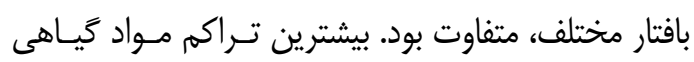

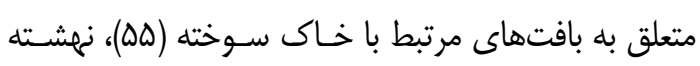

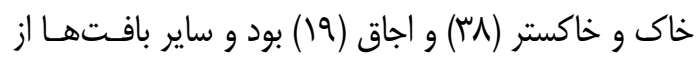

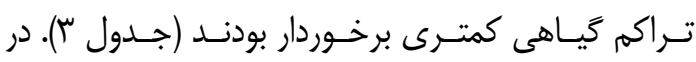

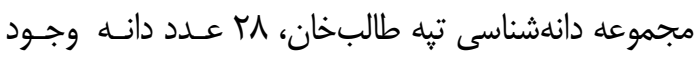
داشتند كه بر اساس شكل و اندازه، به احتمال زياد، متعلق به گياهان خودرو يا وحشى بودند، ولى به دليل عدم وجـود

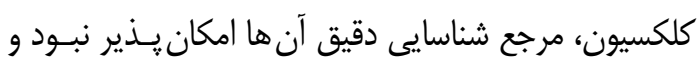

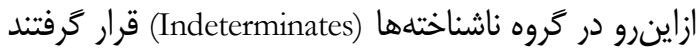

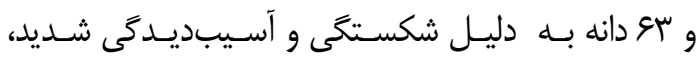

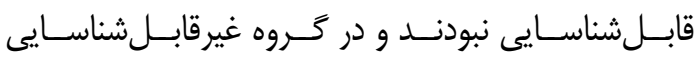

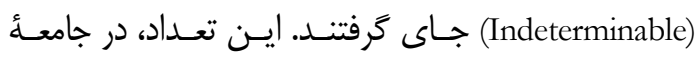
آمارى در نظر گرفته نمىشوند. نتايج مطالعات دانهشناسـى انجام گرفته بر دو هزار و هأ قطعـه دانسه و ميـوه (سـالم و

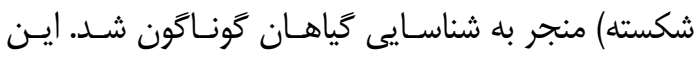
كياهان شامل هفت تيره (Family) نوزده جنس (Genus) و

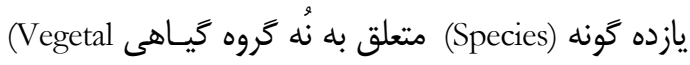
group)

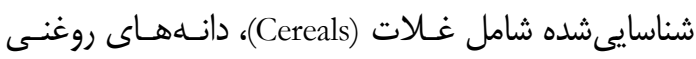

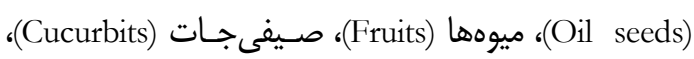
حبوبات كشتشده (Cultivated pulses)، حبوبـات وحشىى ميوهى (W.

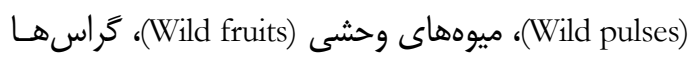
و كياهان خودرو (Wild grasses) اين ميان، غلات، دانههاى روغنى، ميوهها، صـيفى جـات و وردات

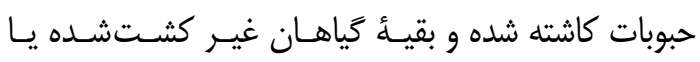

وحشى (Non cultivated plants) بودهاند (شكل (1).

\section{الف. تَياهان كثتشده} ا. غلات: از ميان گياهان كشت شده در تِه طالبخـان در

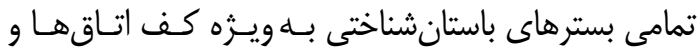

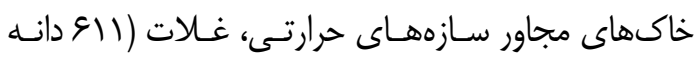
سالم، شكسته و اجزاى ساقه) در مقايسه با ديخــــ گياهـان كشتشده، وفـور بيشـترى دارنـد. غـلات شناسـايى شـــه

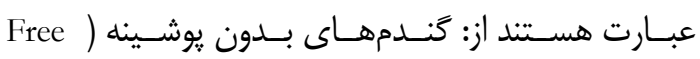
(threshing wheat

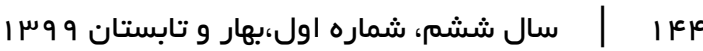


(Suaeda sp.)

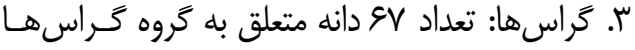

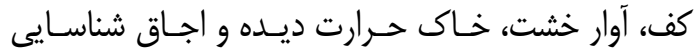

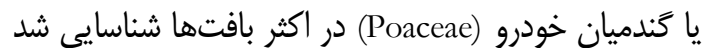
شدند. تراكم بقاياى گَياهان خودرو بر كفهاى اسـتقرارى

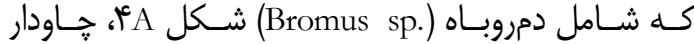

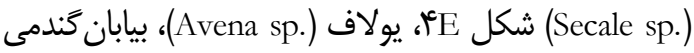
(Aegilops sp.) شكل B'أ، مادر گَندم (Eremopyrum sp.) و جمن (Lolium sp.) بودند (شكل 9). أ. ميوههاى وحشى: بقاياى ميوههاى وحشسى شـامل

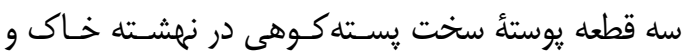
اجاق شناسايى شدند (شكل سأl). بيشتر از ساير بافتها بود (شكل ^).

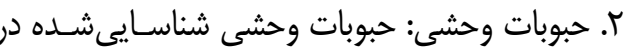

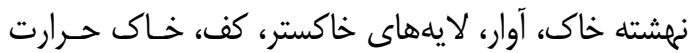
ديـده و اجـاق شـامل اهم دانـه گَـون (Astragalus sp.)،

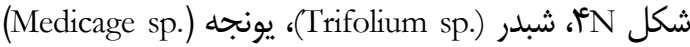
شكل Mcl أكليـل كـوهى (cf. Rosmarinus officinalis)، اســرس (Onobrychis sp.) و تيـره حبوبـات (Fabaceae)

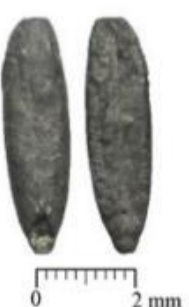

A
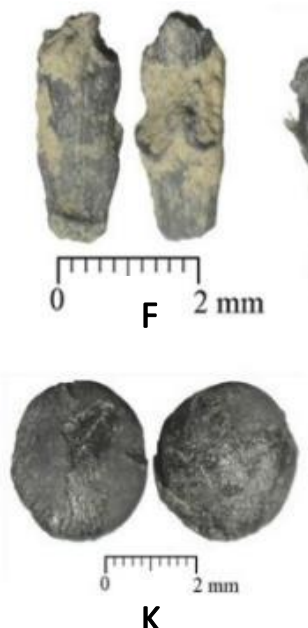

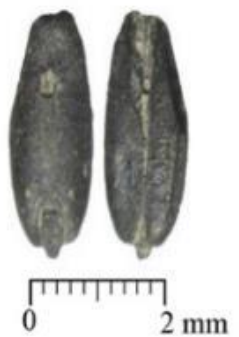

B
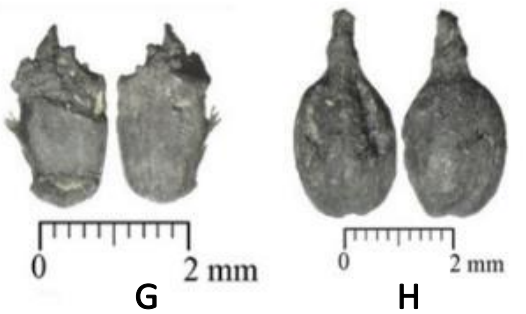

$\mathrm{H}$

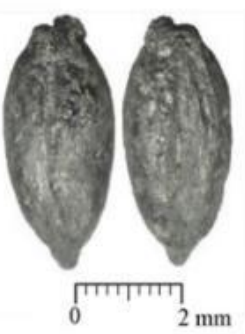

D
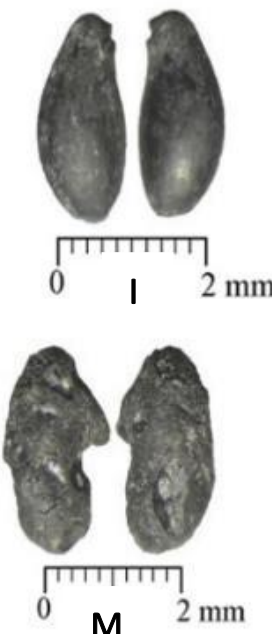

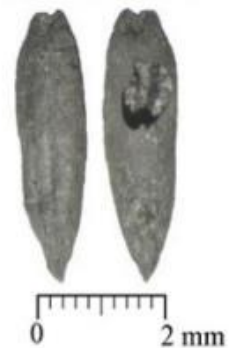

E
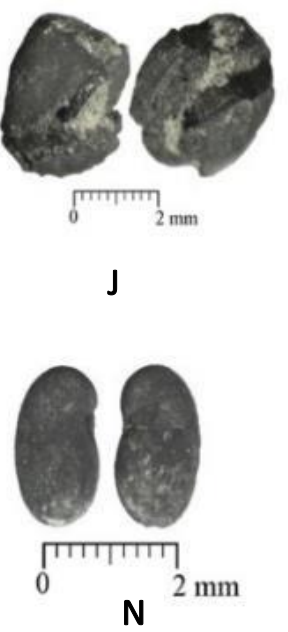

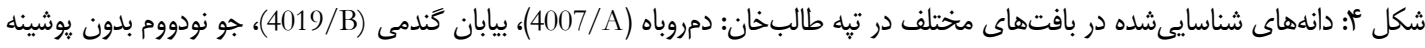

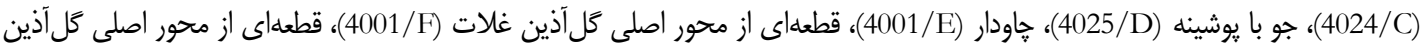

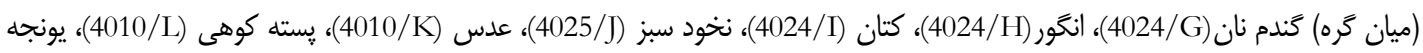

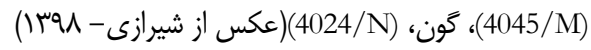

Fig. 4: Identified seeds in various contexts at Tepe Taleb Khan: brome grasse/Bromus sp.(4007/A), grass family/Ermopyrum sp. (4019/B), caryopsis from a free threshing barley, /Hordeum vulgar var. nudum (4024/C), caryopsis from a hulled barley, Hordeum vulgare (4025/D), rye/Secale sp. (4001/E), rachis segment from cereals indeterminate/Cerealia (4001/F), rachis segment, internode from a free threshing wheat of bread wheat type/ Triticum cf. aestivum (4024/G), grape/Vitis vinifera $(4024 / \mathrm{H})$, flax/Linum usitatissimum (4024/I), pea/Pisum sativum (4025/J), lentil/Lens culinaris (4010/K), fruit stone from wild pistachio/Pistacia sp. (4010/L), medick/Medicago sp. (4045/M), goat's thorn/Astragalus sp. (4024/N) (Photo: Shirazi, 2020) 


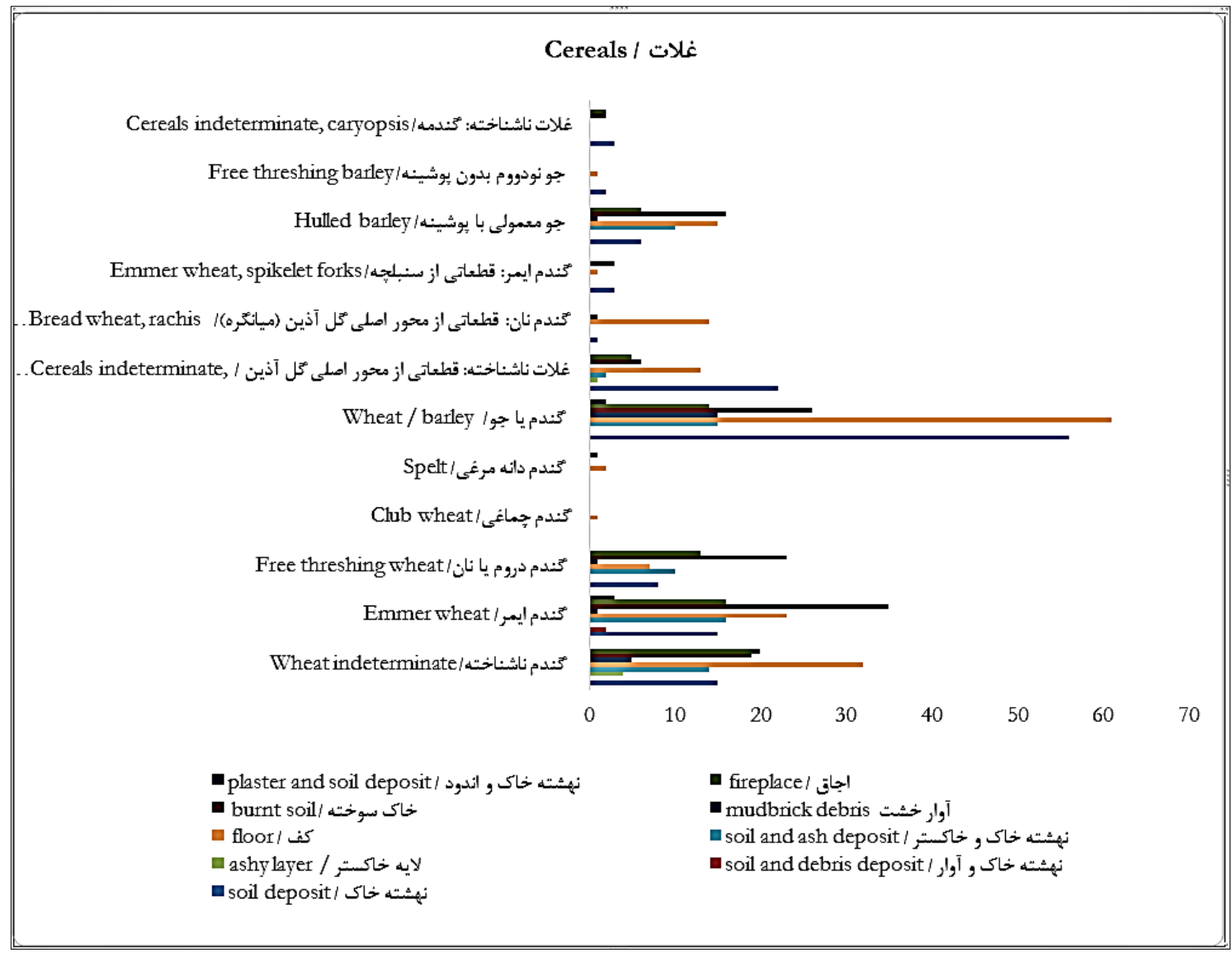

شكل ه: يراكنش و تعداد غلات شناسايىشده در تبه طالبخان

Fig. 5: Distribution and number of identified cereals at Tepe Taleb Khan

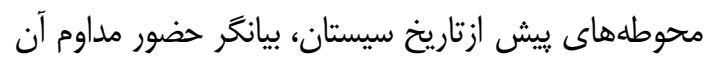

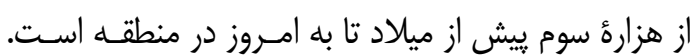

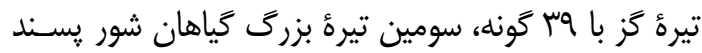

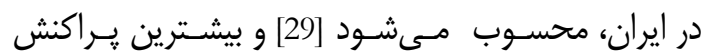

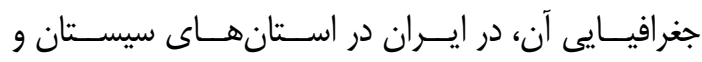
بلوجستان و كرمان است [30].

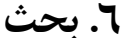

شواهد كَياهباستانشناسى يافت شـــه در تِّهـ طالـبـــان

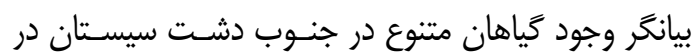

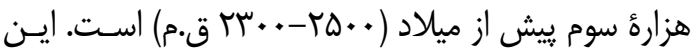
شواهد مشابه كَياهان شناسايىشده در شهر سـوخته اسـت

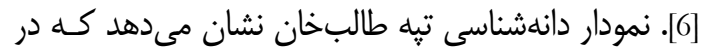

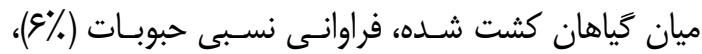

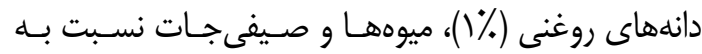

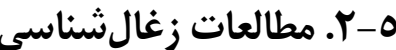

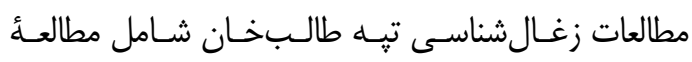
ميكروسكويى ^^و قطعه زغال جوب به دست آمده از بافتار

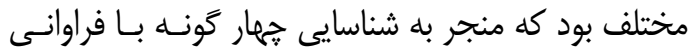

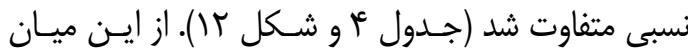

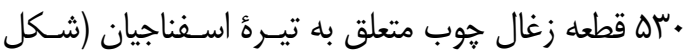

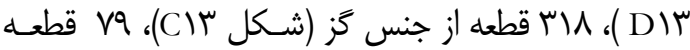

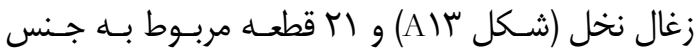

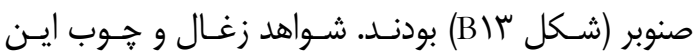
دانتان، ييشازاين نيز از تمامى دورههاى شهر سوخته -IV)

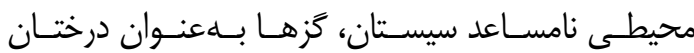
خشكى يسند و نمك دوست، گياه غالب منطقه هستند امـا

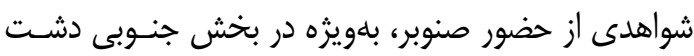

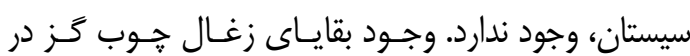

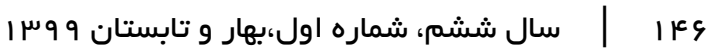




لدو فصلنامه يزووهه باستانسنجى

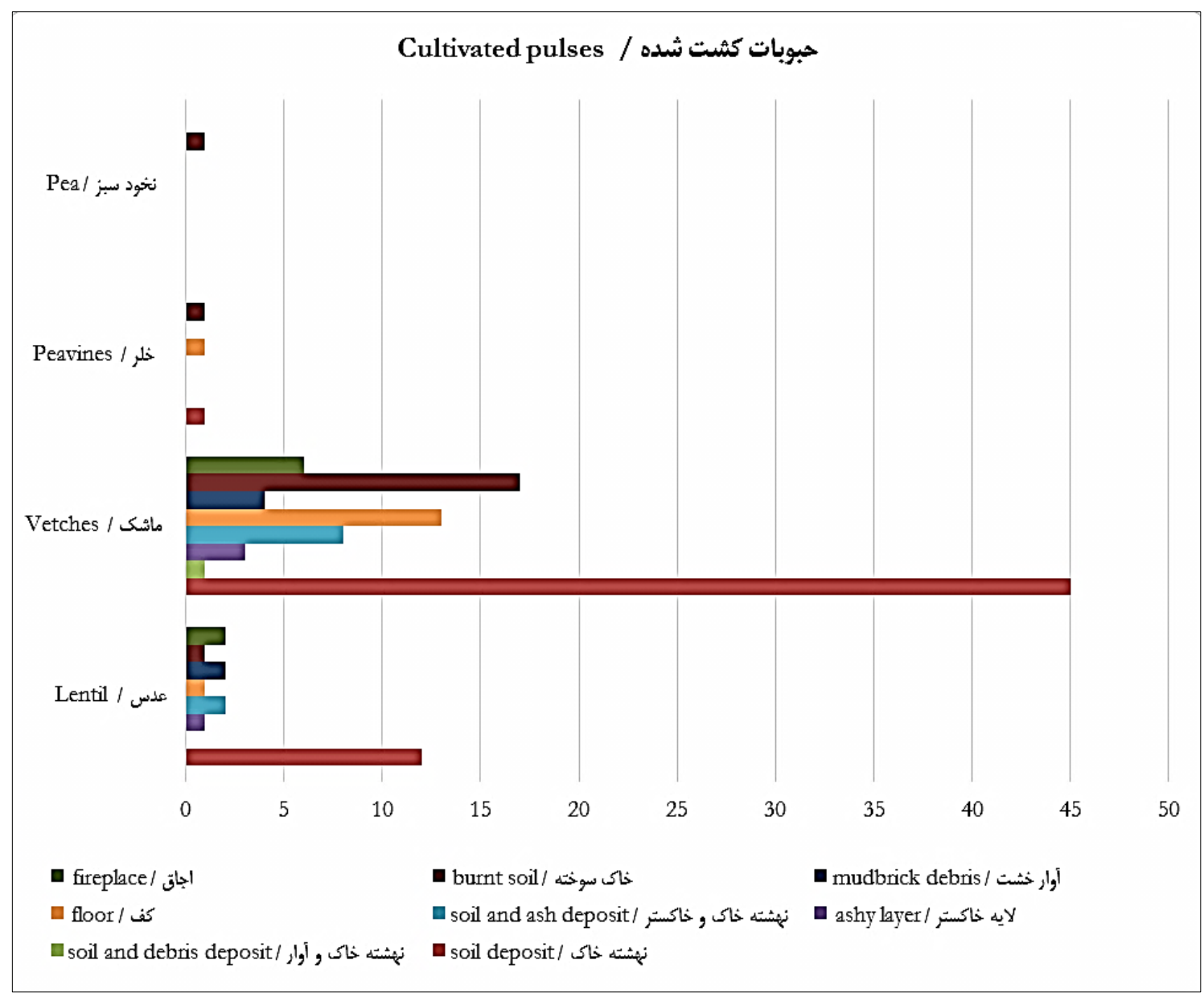

شكل و: يراكنش و تعداد حبوبات شناسايى شده در تبه طالبخان

Fig. 6: Distribution and number of identified pulses at Tepe Taleb Khan

\section{Flax / كتان}

خاك سوخته / خ /

كف / floor

soil and debris deposit / نهشته خاك و آوار

soil deposit / نهته خاك
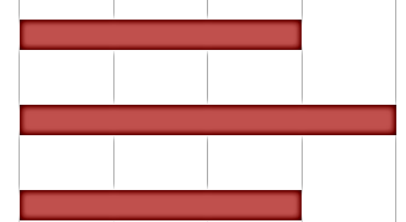

0

5

شكل ₹: يراكنش و تعداد كتان شناسايىشده در تِيه طالبخان

Fig. 7: Distribution and number of identified flax at Tepe Taleb Khan 


\section{Wild plants / تياهان خودرو}

Lily family / سوسنيان

Goosefoots family / اسفناجيان

Seepweeds / كاكل

Goosefoots / سلمه تره

شير هنير / Bedstraw

هickwheat family / هفت بنديان

هفت بند / Smart weed

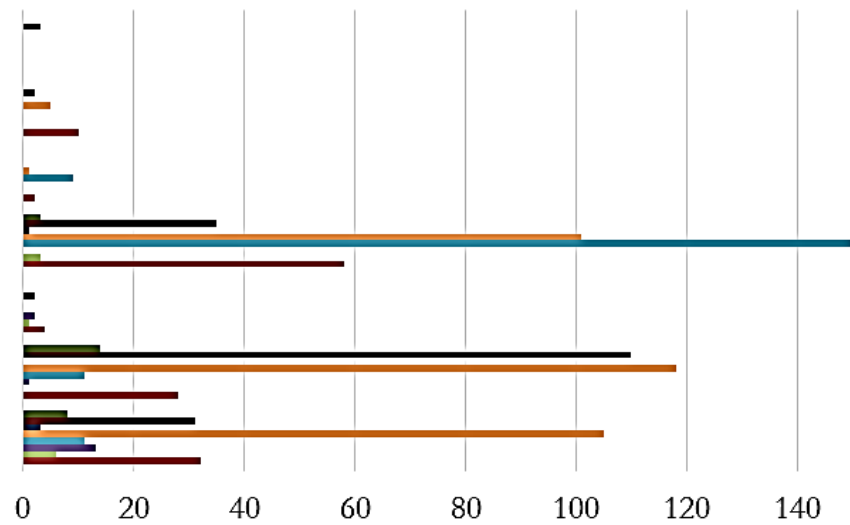

- الجاق / fireplace

- أوار خشت / mudbrick debris

U soil and ash deposit / نهشته خاك و خاكست

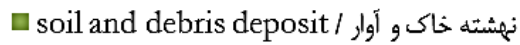

Q خاك سوخته / burnt soil

afloor/

Q لايه خاكستر / ashy layer

ت نهشته خاك / Soil deposit

شكل مُ يراكنش و تعداد كياهان خودرو شناسايىشده در تِّه طالبخان

Fig. 8: Distribution and number of identified wild plants at Tepe Taleb Khan

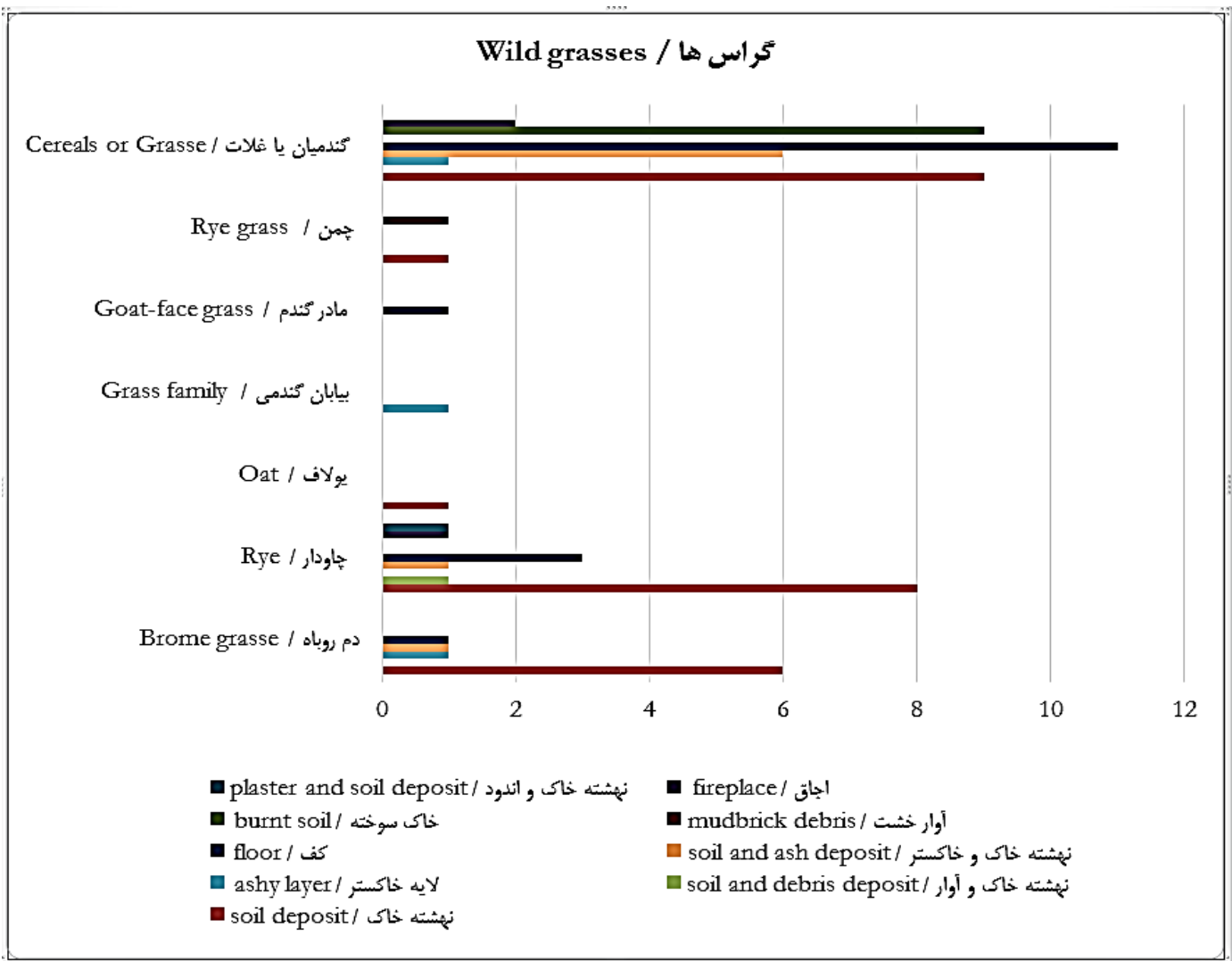

شكل ج: يراكنش و تعداد گراسهاى شناسايىشده در تِه طالبخان

Fig. 9: Distributin and number of identified wild grasses at Tepe Taleb Khan 


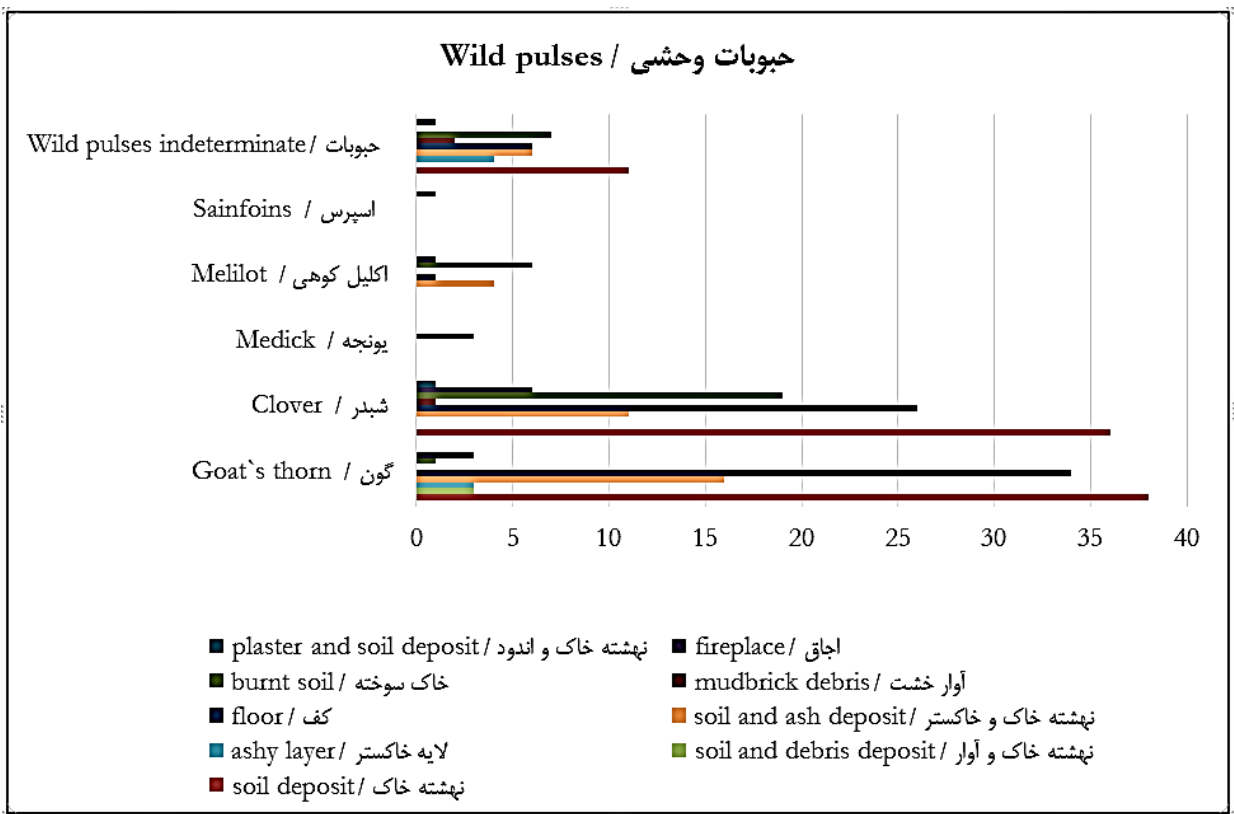

شكل • ا: براكنش و تعداد حبوبات وحشى شناسايىشده در تِّه طالبخان

Fig. 10: Distribution and number of identified wild pulses at Tepe Taleb Khan

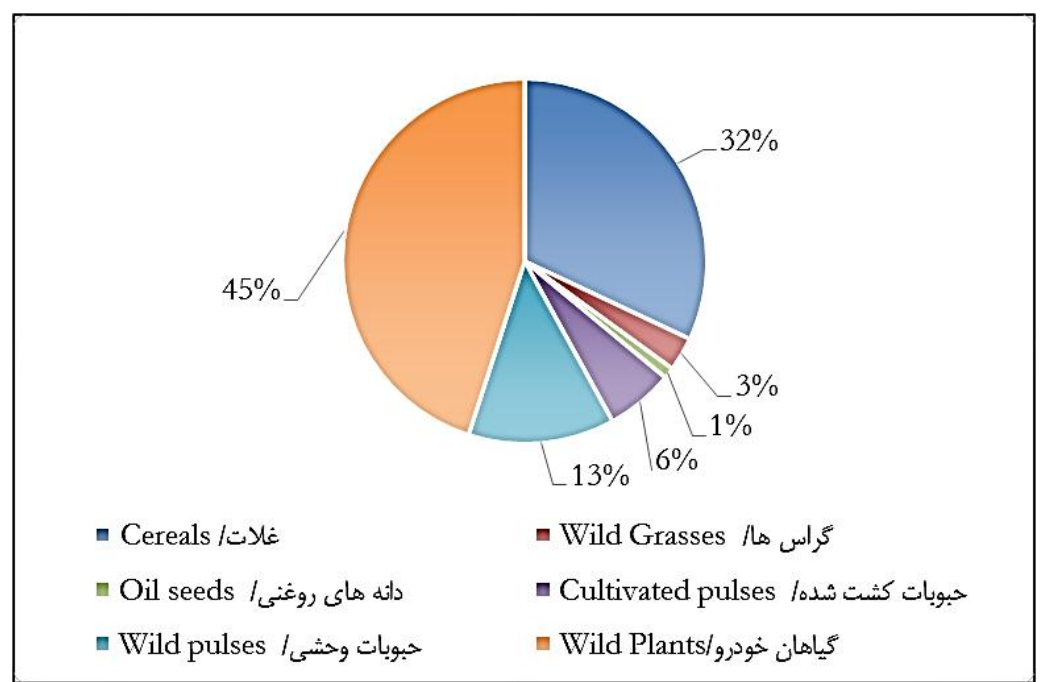

شكل |(ا: نمودار دانهشناسى، فراوانى نسبى كياهان شناسايىشده در تِه طالبخان

Fig. 11: Carpological diagram, relative frequency of plant identified at Tepe Taleb Khan

مشاهده مىشود. يِيشازايـن نيـز بقايـاى ايـن كياهـان از

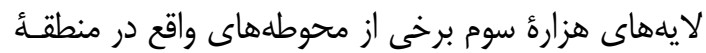

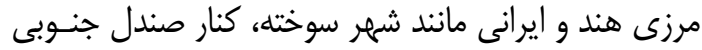

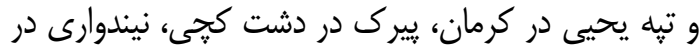

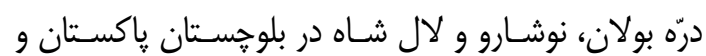
مونديخك در قندهار افغانستان تزارش شده است لـان -12-2].

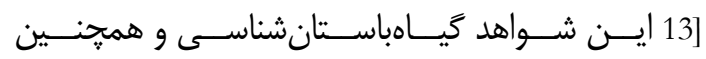

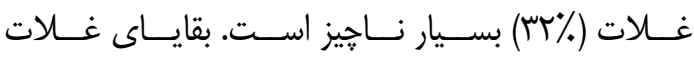

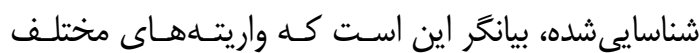
كَندم و جو منبع غذايى اصـلى سـاكنان تيـه طالبخدان

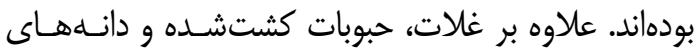

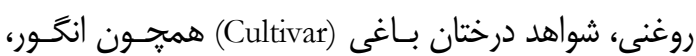

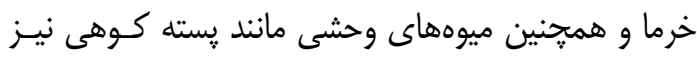
در نمودار دانـشناسـى و زغـالشناسـى تيـه طالـبنـان

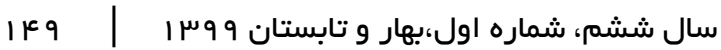


جدول †: نتايج زغالشناسى در تيه طالبخان

Table 4: Anthracological results at Tepe Taleb Khan

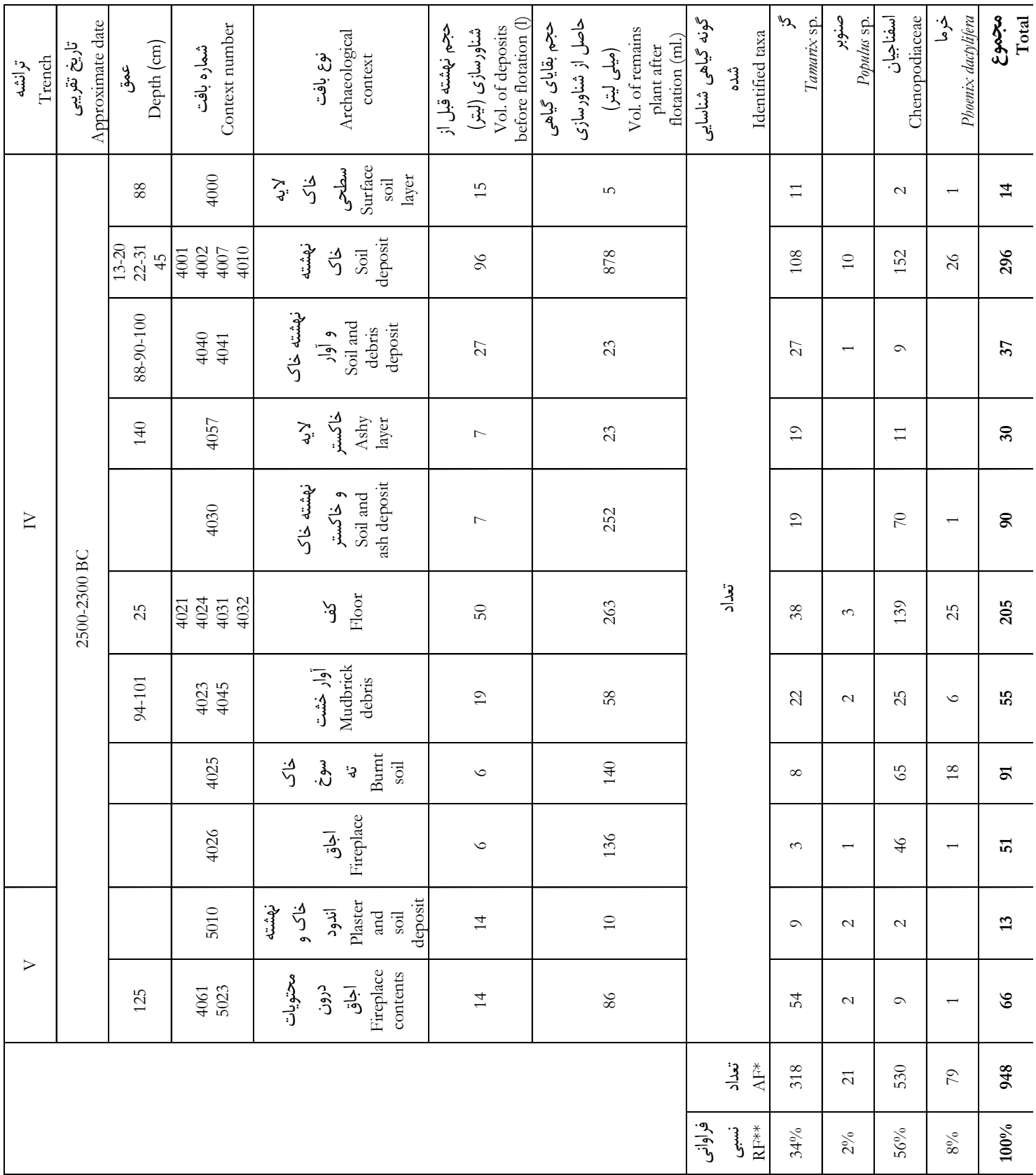

* Absolute Frequence; ${ }^{* *}$ Relative Frequence

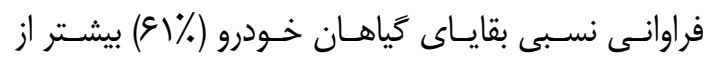

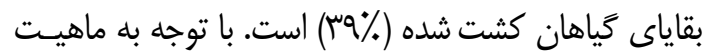
بافتارهايى (نهشته خاك، آوار، اجاق، كف و دورريزها) كـهـ

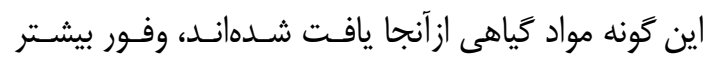

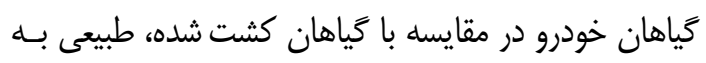
نظر مىرسد. در ميان بقاياى گياهان خودرو شناسايىشده،

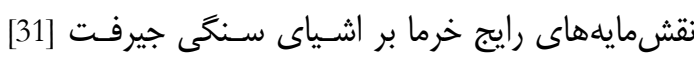

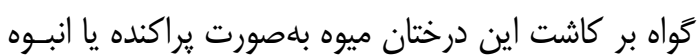
و يا وجود مبادلات شبكههاى تجـارى ايـن محصـول در در دراه منطقة مرزى هند و ايرانى در هزارة سوم يــيش از مـيلاد،

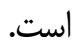

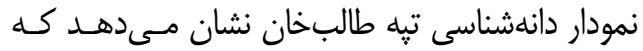

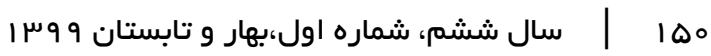




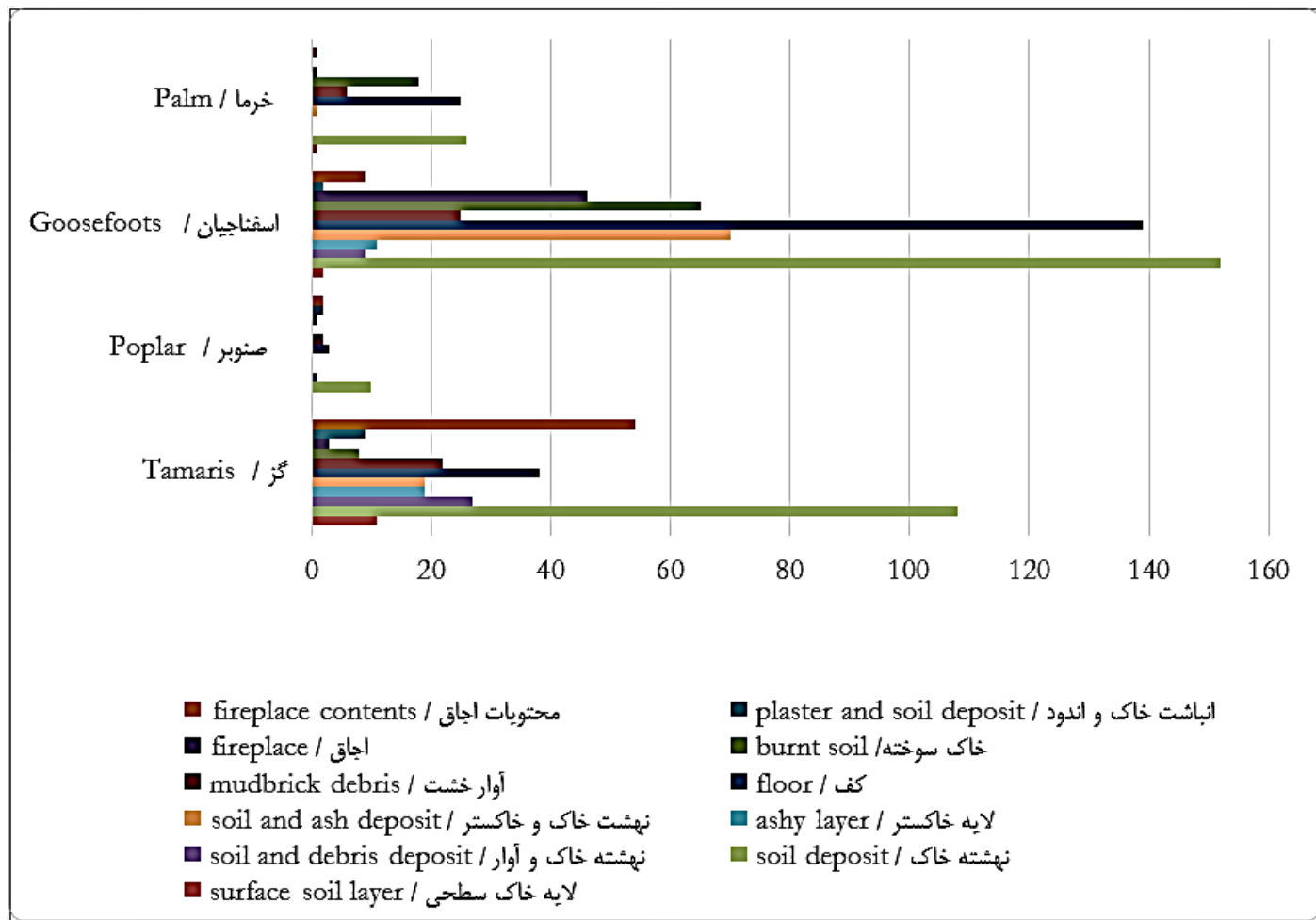

$$
\text { شكل rا: يراكنش و تعداد كَونها و ساختارهاى گَياهى شناسايىشده در تِه طالبخان }
$$

Fig. 12: Distribution and number of identified species and vegetal formations at Tepe Taleb Khan

ميلاد است. اين، خـود خَـواهى بــر وجـود نـوعى اقتصـاد معيشتى بر يايه كشاورزى در منطقه است. حضـور نباتـات علوفهاى، حبوبات وحشى و علفهاى هرز كــه بــه همــراه

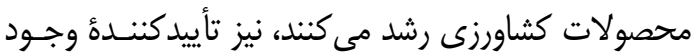
مزارع كشاورزى در جلخه حاصلخيز دلتاى هيرمند در ايـن دوره هستند. ساكنان تيه طالبخــان بـراى رفـع نيازهـاى

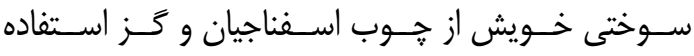
مى كردهاند. اين خوبهها كه داراى بـافتى نـرم و خاصـيت

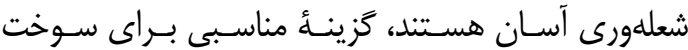
اجاقها، تنورها و بهاحتمال زياد، كورهها بـودهانـد. شـواهد

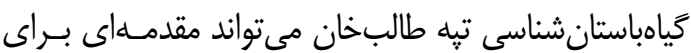
ادامه مطالعات كياهباستانشناسى در ديخــر محوطـهـهـاى

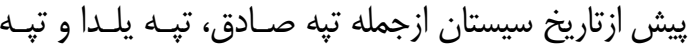

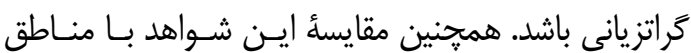

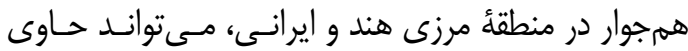

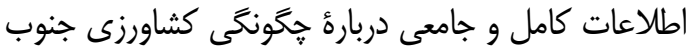

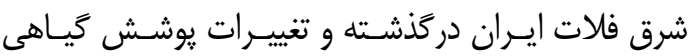
دشت سيستان باشد.
بقاياى زغال جوب و دانـه سـلمهتـره از تيـره اسـفناجيان،

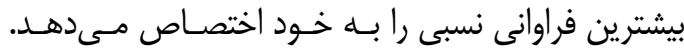

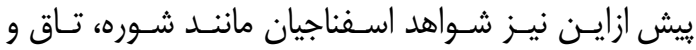
سلمهتره سـفيد (Chenopodieum alba) از شـهر سـوخته كزارش شده است [6-2]. فراوانى نسبى بالاى اين گياهـان،

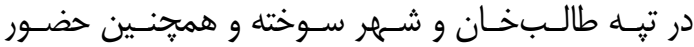

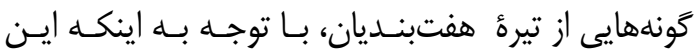

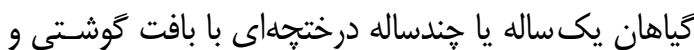
ذخيره كنندهُ آب و مقاوم در برابـر تجمـع زيـاد امـلاح در

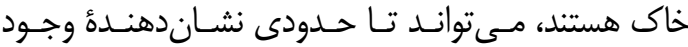
كياهان استيى سازگًار با فصول خشك و خاكهــاى شـور جنوب دشت سيستان در هزارهٔ سوم ييش از ميلاد باشند.

\section{V. نتيجه كَيرى و بيشنهادات}

تشابه گونههاى گياهى شناسايى شده در تيه طالـبخـان و ديخر محوطههاى ييش ازتاريخ دشـت سيسـتان همجــون شهر سوخته بيانكَر كاشت كياهان زراعى ازجملـه غـلات،

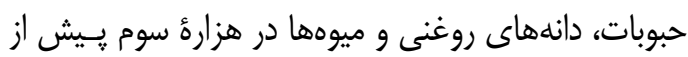




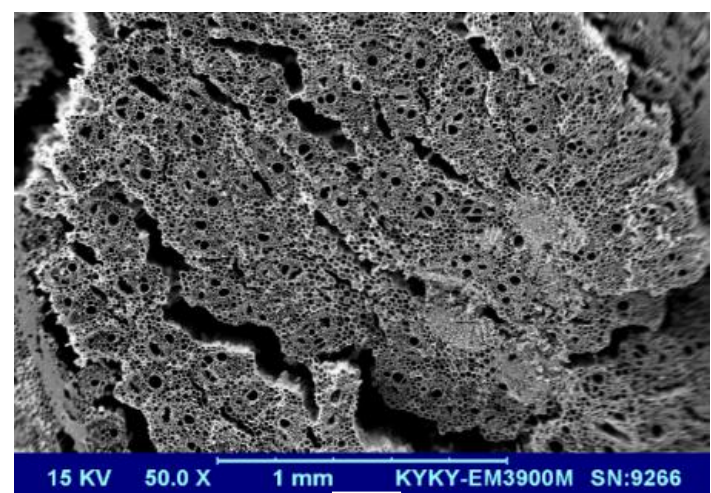

A

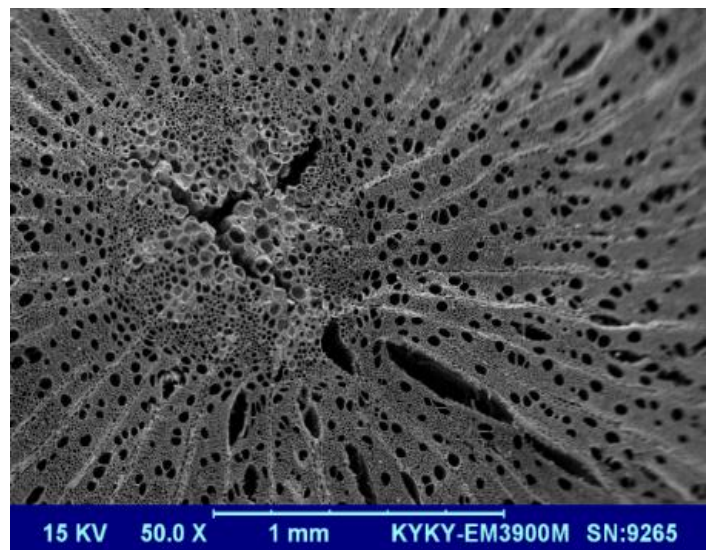

C

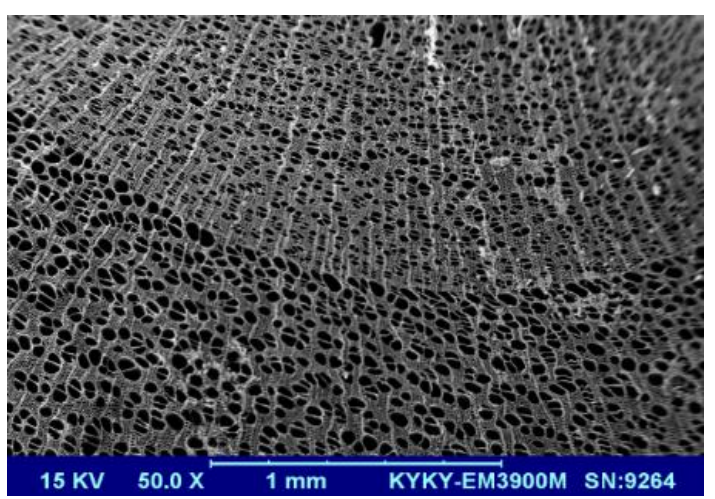

B

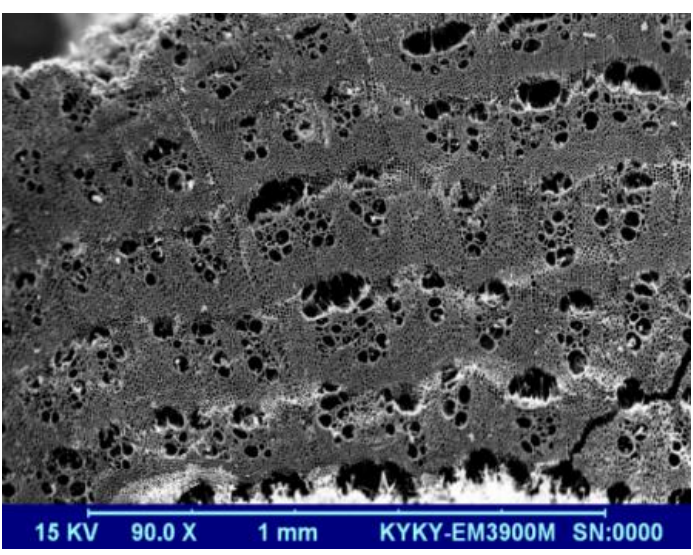

D

شكل سا: برش عرضى زغال جوب شناسايىشده در نهشته خاك: خرما(A) ، صنوبر (B) ، كز (C) و اسفناجيان) (D) عكس: ميكروسكوٍ الكترونى

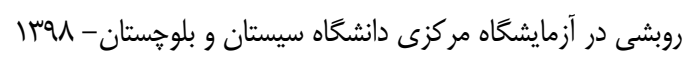

Fig. 13: Transeversal section of charcoal identified in soil deposit: palm (A), poplar (B), tamaris (c) and goosefoots (D) (Photo: Central Laboratory of the University of Sistan and Baluchestan 2020)

دانشجويان ورودى +9 رشتأ باستانشناسى دانشگاه زابل كه ياريخر ما بودهاند، تقدير و تشكر مى كنـــــ همرجنـين

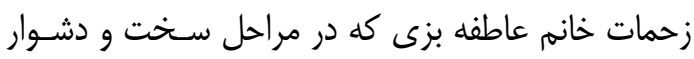

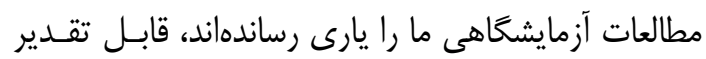

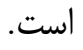

\section{Reference}

[1] Mehrafarin R, Sajjadi M. S. Effects of hydrology and geographical environment on ancient settlements in Zahak region of Sistan, Journal of Spatial Planning. 2005; 9(1): p. 217-239. [in Persian] [مهرآفرين رضا، سيدسجادى سيدمنصور. تأثير هيدرولوزى :

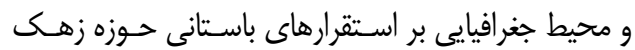

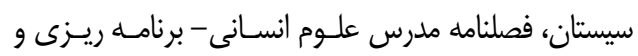

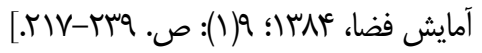

[2] Costantini L, Costantini Biasini L. Agriculture in Baluchistan between the 7th and the 3rd Millennium B. C. Newsletter of Baluchistan Studies. 1985(2):16-30.

[3] Costantini L. Wood remains from Shahr-i Sokhta: a source of information for the ancient environment and technology in photohistoric Sistan. InSouth Asian Archaeology 1977 (pp. 87-121).

[4] Costantini L. Introductory note on burnt wood residues from Shahr-i Sokhta, Iran.

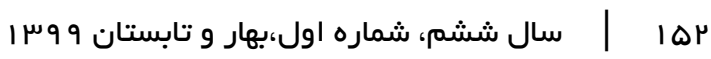


East and West. 1977 Dec 1;27(1/4):105110.

[5] Tucci GI, BASAGLIA P. La città bruciata del deserto salato: testi di Basaglia. [et al.]. Erizzo; 1977.

[6] Shirazi Z. Vegetal resources of southern Sistan during the third millennium BC, based on the archaeobotanical evidence at Shahr-i Sokhta.In: M. S. Seyyed Sajjadi and E. Ascalone (eds). 2019. [in persian]

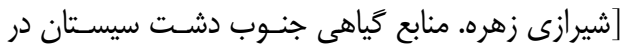

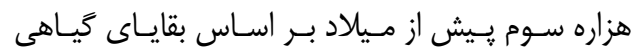

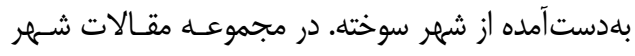

$$
\begin{aligned}
& \text { سوخته r. به كوشش سيدمنصور سيدسـجادى و انريكـو }
\end{aligned}
$$

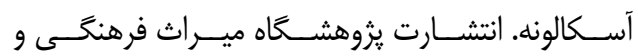

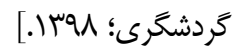

[7] Karami M. Kavosh H. A., Ghasemi M., Miri M. Typology and classification of Tappe Taleb Khan potteries in Sistan, based on comparative studies with adjacent areas [in:] "proceeding of international congress of young archaeologist", M. H. A. Kharanaghi. M. Khanipoor., R. Naseri (eds.), Tehran: Iranology Foundation, 2018: p. 367-382. [in Persian]

$$
\begin{aligned}
& \text { [كرمى محبوبه، كاوش حسين علىى، قاسـمى محسـن و }
\end{aligned}
$$

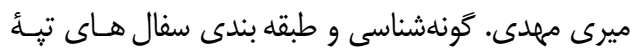

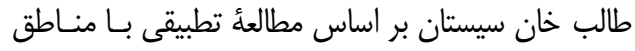

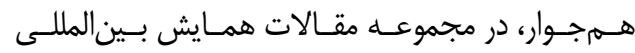

$$
\begin{aligned}
& \text { باستان شناسان جوان (جلد اول)، به كوشش: مجران محمدحسين }
\end{aligned}
$$

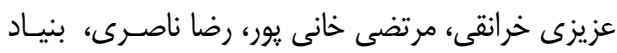

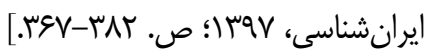

[8] Biscione RA. The Burnt Building of Period Shahr-i Sokhta IV. An Attempt of Functional Analysis from the Distribution of Pottery Types. Seminario di studi asiatici, series minor. 1979;10:291-306..

[9] Kavosh H. A. Southern Plain of Sistan During Bronze Age (doctoral dissertation), Tehran University, Tehran, Iran. (2012). [in persian]

$$
\begin{aligned}
& \text { [كاوش حسين على دشـــ جنـوبى سيسـتان در عصـر }
\end{aligned}
$$

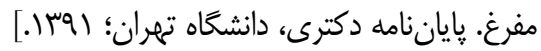

[10] Ghanavati F, Moradi F, Mozaffari J. Plant dictionary of Sistan and Baluchestan province. Agriculture organization of Sistan and Baluchestan province. Management of education and popular participation; 2004. [in Persian]

$$
\begin{aligned}
& \text { [قنواتى فرنغيس، مرادى فؤاد و مظفرى جـواد. فرهنـع }
\end{aligned}
$$

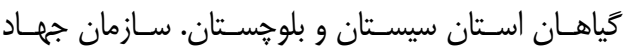

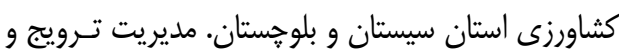

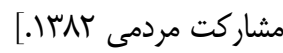

[11] Meadow R. H. "The geographical and palaeoenvironmental setting of Tepe Yahya (Ch. 3)". In: C.C. LambergKarlovsky ET T. W. BEAL (éds.) Excavations at Tepe Yahya, Iran 19671975. The early periods. Peabody Museum of Archaeology and Ethnology, Harvard University, Cambridge MA, 1986: p. 2138.

[12] Tengberg M. L'exploitation et utilisation des plantes dans les confins indo-iraniens du Chalcolithique à l'âge du Bronze selon les recherches archéobotaniques, In: Y. Madjidzadeh (éd.), First International Conference of Archaeological Research in Jiroft 2004. Cultural Heritage, Handicraft and Tourism Organization of Kermân Province, International Centre for Archaeological Research of Southeast Region, Jiroft. 2008: p. 169-179.

[13] Mashkour M, Tengberg M, Shirazi Z, Madjidzadeh Y. Bio-archaeological studies at Konar Sandal, Halil Rud basin, southeastern Iran. Environmental Archaeology. 2013 Oct 1;18(3):222-46.

[14] Shirazi R, Shirazi Z. Vegetation Dynamic of Southern Sistan during the Bronze Age: Anthracological Studies at Shahr-i Sokhta. Iranian Journal of Archaeological Studies. 2012 Sep 1;2(1):27-38.

[15] Vaezi A, Ghazban F, Tavakoli V, Routh J, Beni AN, Bianchi TS, Curtis JH, Kylin H. A Late Pleistocene-Holocene multi-proxy record of climate variability in the Jazmurian playa, southeastern Iran. Palaeogeography, Palaeoclimatology, Palaeoecology. 2019 Jan 15;514:754-67..

[16] Hamzeh MA, Mahmudy-Gharaie MH, Alizadeh-Lahijani H, Moussavi-Harami R, Djamali M, Naderi-Beni A. Paleolimnology of Lake Hamoun (E Iran): implication for past climate changes and possible impacts on human settlements. Palaios. 2016 Dec 1;31(12):616-29.

[17] Gurjazkaite K, Routh J, Djamali M, Vaezi A, Poher Y, Beni AN, Tavakoli V, Kylin H. Vegetation history and humanenvironment interactions through the late 
Holocene in Konar Sandal, SE Iran. Quaternary Science Reviews. 2018 Aug 15;194:143-55.

[18] Zohary D, Hopf M, Weiss E. Domestication of Plants in the Old World: The origin and spread of domesticated plants in Southwest Asia, Europe, and the Mediterranean Basin. Oxford University Press on Demand; 2012.

[19] Struwe L. Field identification of the 50 most common plant families in temperate regions.

[20] Kamilya P, Das A, Das A, Sarkar A. Comparative analysis of major phenotypical traits of some Dicotyledonous weed seedlings of crop fields of Balurghat Block, Dakshindinajpur, West Bengal.

[21] Jacomet S. Identification of cereal remains from archaeological sites. Basel University, Basel. 2006.

[22] Mackizadeh Tafti M, Sharifi Ashourabadi E. Atlas of the Seeds of Medicinal plants. Research Institute of Forests and Rangelands. 2017; 1. [In Persian]

$$
\begin{aligned}
& \text { [مكــزاده تفتـى مـريه، شـريفى عاشـور آبادى ابـراهيه. }
\end{aligned}
$$

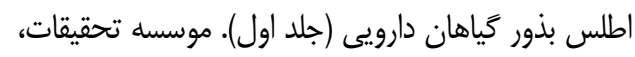

$$
\begin{aligned}
& \text { جنگل ها و مراتع كشور، عوسا.] }
\end{aligned}
$$

[23] Baas P, Gasson PE, Wheeler EA, editors. IAWA list of microscopic features for hardwood identification: with an appendix on non-anatomical information. National Herbarium of the Netherlands; 1989.

[24] Paulssen LM. Identification of active charcoals and wood charcoals. Identification of active charcoals and wood charcoals. 1964.

[25] Parsa Pajouh D, Schweingruber FH. Atlas des bois du nord de l'Iran. Description anatomique et identification microscopique des essences principales.

[26] Neumann, K. S. Détienne, W. P. Schweingruber, F.H. Wood of the Sahara and the Sahel. Birmensdorf, Eidg. Forschungsanstalt WSL. Haupt Verlag, Bern/ Stuttgart/Wien. 2000.

[27] Niloufari P. Textebook of wood technology. University of Tehran Publication. 1986: 737. [In Persian]

$$
\begin{aligned}
& \text { [نيلوفرى يرويز. جوبشناسى ₹وبهاى ايران. انتشـارات }
\end{aligned}
$$

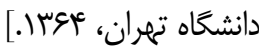

[28] Hejazi R. Principales of wood anatomy. Dehkhoda Publication; 1979. [In Persian]

$$
\begin{aligned}
& \text { ]جازى رضـا. اصـول تشـريح جـوب (تشـريح و كليـد }
\end{aligned}
$$

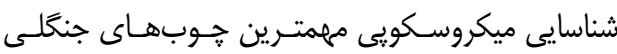

$$
\begin{aligned}
& \text { ايران). انتشارات كتابفروشى دهخدا، مهَّا. }
\end{aligned}
$$

[29] Akhani H. Biodiversity of halophytic and sabkha ecosystems in Iran. InSabkha ecosystems 2006 (pp. 71-88). Springer, Dordrecht.

[30] Asadi M. Flora of Iran. Research Institute of Forests and Rangelands.1989; 1. [In Persian]

$$
\begin{aligned}
& \text { [اسدى مصطفى. فلور ايران. انتشارات موسسه تحقيقات، }
\end{aligned}
$$

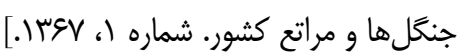

[31] Perrot J, Madjidzadeh Y. L'iconographie des vases et objets en chlorite de Jiroft (Iran). Paléorient. 2005 Jan 1:123-52. 